\title{
Antiviral treatment perspective against Borna disease virus 1 infection in major depression: a double-blind placebo- controlled randomized clinical trial
}

Detlef E. Dietrich ${ }^{1,2,3^{*+}} \mathbb{D}$, Liv Bode ${ }^{4^{*+}}$, Carsten W. Spannhuth ${ }^{3}$, Hartmut Hecker ${ }^{5}$, Hanns Ludwig ${ }^{4}$ and Hinderk M. Emrich ${ }^{3}$

\begin{abstract}
Background: Whether Borna disease virus (BDV-1) is a human pathogen remained controversial until recent encephalitis cases showed BDV-1 infection could even be deadly. This called to mind previous evidence for an infectious contribution of BDV-1 to mental disorders. Pilot open trials suggested that BDV-1 infected depressed patients benefitted from antiviral therapy with a licensed drug (amantadine) which also tested sensitive in vitro. Here, we designed a double-blind placebo-controlled randomized clinical trial (RCT) which cross-linked depression and BDV-1 infection, addressing both the antidepressant and antiviral efficacy of amantadine.

Methods: The interventional phase II RCT (two 7-weeks-treatment periods and a 12-months follow-up) at the Hannover Medical School (MHH), Germany, assigned currently depressed BDV-1 infected patients with either major depression (MD; $N=23$ ) or bipolar disorder (BD; $N=13$ ) to amantadine sulphate (PK-Merz ${ }^{\circledR}$; twice $100 \mathrm{mg}$ orally daily) or placebo treatment, and contrariwise, respectively. Clinical changes were assessed every $2-3$ weeks by the 21-item Hamilton rating scale for depression (HAMD) (total, single, and combined scores). BDV-1 activity was determined accordingly in blood plasma by enzyme immune assays for antigens (PAG), antibodies (AB) and circulating immune complexes $(\mathrm{ClC})$.
\end{abstract}

Results: Primary outcomes ( $\geq 25 \%$ HAMD reduction, week 7) were $81.3 \%$ amantadine vs. $35.3 \%$ placebo responder ( $p=0.003)$, a large clinical effect size (ES; Cohen's d) of 1.046, and excellent drug tolerance. Amantadine was safe reducing suicidal behaviour in the first 2 weeks. Pre-treatment maximum infection levels were predictive of clinical improvement ( $A B, p=0.001 ; P A G, p=0.026$; HAMD week 7). Respective PAG and CIC levels correlated with $A B$ reduction ( $p=0,001$ and $p=0.034$, respectively). Follow-up benefits (12 months) correlated with dropped cumulative infection measures over time $(p<0.001)$. In vitro, amantadine concentrations as low as $2.4-10 \mathrm{ng} / \mathrm{mL}$ (50\% infection-inhibitory dose) prevented infection with human BDV Hu-H1, while closely related memantine failed up to $100,000-$ fold higher concentration $(200 \mu \mathrm{g} / \mathrm{mL})$.

(Continued on next page)

\footnotetext{
* Correspondence: detlef.dietrich@burghof-klinik.de; liv.bode@web.de

${ }^{\dagger}$ Detlef E. Dietrich and Liv Bode contributed equally to this work.

'Department of Psychiatry, Burghof-Clinic, Ritterstr. 19, 31737 Rinteln,

Germany

${ }^{4}$ Joint Senior Scientists, Freelance Bornavirus Workgroup, Beerenstr. 41, 14163

Berlin, Germany

Full list of author information is available at the end of the article
}

(C) The Author(s). 2020 Open Access This article is distributed under the terms of the Creative Commons Attribution 4.0 International License (http://creativecommons.org/licenses/by/4.0/), which permits unrestricted use, distribution, and reproduction in any medium, provided you give appropriate credit to the original author(s) and the source, provide a link to the Creative Commons license, and indicate if changes were made. The Creative Commons Public Domain Dedication waiver (http://creativecommons.org/publicdomain/zero/1.0/) applies to the data made available in this article, unless otherwise stated. 
(Continued from previous page)

Conclusions: Our findings indicate profound antidepressant efficacy of safe oral amantadine treatment, paralleling antiviral effects at various infection levels. This not only supports the paradigm of a link of BDV-1 infection and depression. It provides a novel possibly practice-changing low cost mental health care perspective for depressed BDV-1-infected patients addressing global needs.

Trial registration: The trial was retrospectively registered in the German Clinical Trials Registry on 04th of March 2015. The trial ID is DRKS00007649; https://www.drks.de/drks_web/setLocale_EN.do

Keywords: Major depression, bipolar disorder, Borna disease virus 1 (BDV-1), antiviral treatment, amantadine, double-blind placebo-controlled randomized clinical trial (RCT)

\section{Background}

Mental health was given a global health priority by the World Health Assembly in 2013 [1]. As many as 700 million people $(7.4 \%)$ were affected by mental disorders according to the 2010 Global Burden of Disease Study, accounting for both a huge individual and societal burden, with societal costs of $\$ 2.5$ billion in 2010, and projections of $\$ 6$ billion by 2030 [1]. Depressive disorders contributed to the largest proportion (40.5\%) of disability-adjusted life years (DALYs) within mental diseases. They accounted for almost one third of the global suicide burden (10.4 of 36.2 million DALYs), over $80 \%$ attributable to low and middle income countries [2].

Antidepressants are first-line treatments for depression at least in high-income countries. Up to recent generation antidepressants, serotonin reuptake inhibitors (SSRIs), they are all based on the concept of monoamine deficiency in depression, and therefore increase levels of serotonin, norepinephrine and/or dopamine through different mechanisms. However, their limited efficacy has been under intense debate [3], and patients continue to experience low remission rates, delayed therapeutic onset, limited effectiveness in milder depression, intolerability and relapses [4]. The potential antidepressant effects of amantadine, an old enigmatic drug, have been addressed suggesting a versatile pharmacodynamics profile, but whether it acts through low-affinity noncompetitive N-methyl-D-aspartate (NMDA) receptor antagonisms targeting glutamate, or other/combined modes, remained to be determined [5]. A completely novel capacity of amantadine as antiviral compound against human Borna disease virus (BDV-1) strains coincided with antidepressant effects in a BDV-infected patient with therapy-resistant bipolar depression [6]. This serendipitous discovery and further supportive open trials $[7,8]$ led us to conduct a "proof of concept" randomized double-blind placebo-controlled cross-over trial reported here. The novel rationale included a paradigm shift which cross-linked both depression with BDV-1 infection, and anti-BDV capacity of amantadine with antidepressant efficacy in infected patients.
Bornaviruses are unique in that they are evolutionary ancient non-segmented negative-strand ribonucleic acid (RNA) viruses (order Mononegavirales; family Bornaviridae) with nuclear replication [9], covering a host spectrum from reptiles to mammals (> 25\% genetic divergence). Only $\mathrm{BDV}-1$, the evolutionarily youngest prototype of the species Mammalian 1 bornavirus [10], has made it around the globe. BDV-1 strains (classical BDV-1 in humans and mammalian animals) have highly conserved RNA genomes (<5\% divergence) [11, 12], differing largely from a variegated squirrel 1 bornavirus (VSBV-1) which was proposed to underlie three human cases of fatal viral encephalitis in highly exposed squirrel breeders [13]. Classical BDV-1 strains are non-cytolytic, have target cells in brain and blood establishing life-long persistence, and share the ability to cause neurologic and behavioural disorders in mammalian hosts [14]. Although the majority of infections follows a sub-clinical course [15], even deadly outcomes are possible triggered by impaired immune defence [16, 17]. Unexpectedly, BDV-1 caused fatal encephalitis recently occurred in transplant recipients who had received organs from a BDV-1 infected healthy donor [18], and another case was reported unrelated to transplantation [19].

The "mood virus hypothesis" of depression is supported but as yet not confirmed by linking unique BDV properties with lines of evidence from human infection [15-17], namely virus isolates and infection prevalence. Human viruses recovered from psychiatric patients' peripheral blood mononuclear cells cells (PBMCs) [20] and brain [21], were proven to be authentic through marked biological differences to animal viruses [22, 23], despite close genetic relationship [24]. Their acknowledgement was, however, constrained by misconception [25]. Serum antibodies (AB) and BDV-specific RNA in PBMCs worldwide indicated higher infection prevalence of psychiatric patients than controls in many but not all studies [26-38]. Failure of detection of any these markers in psychiatric patients occurred as well [39]. A recent meta-analysis indicated a 3.25 times higher likelihood of BDV infection for depressed than healthy people [40]. 
However, comparability was poor due to differing sensitivity levels of antibody and RNA techniques.

The discovery of circulating immune complexes (CIC) in blood plasma [41] explained that in any BDV-1 infected host, most of plasma $A B$ and antigens ( $N$ and $P$ protein; N/P dimers) (PAG) are bound within CIC, whereas unbound $A B$ as well as PAG are less frequent at the same time.

Our novel RCT rationale aimed to evaluate both the antidepressant and antiviral efficacy of amantadine vs. placebo. Longitudinal clinical profiling mainly by the 21item Hamilton rating scale for depression (HAMD) [42] was paralleled by BDV-1 infection profiling, allowing for the simultaneous quantitative determination of $\mathrm{CIC}$, PAG, and $A B$ through a modular enzyme-immune-assay (EIA) technique [41]. The rationale of a mainly antiviral mode of action for amantadine (1-aminoadamantane) was addressed through in vitro efficacy studies in comparison with the closely related derivative memantine (1amino-3,5-dimethyladamantane).

\section{Methods}

\section{Study Design}

The randomized clinical trial (RCT) was designed as an interventional phase II mono-centre double-blind placebo-controlled cross-over study followed by a 12 months follow-up period (Fig. 1). The cross-over design was an ethical request due to previously beneficial open trials [6-8] and guaranteed that all patients received the same overall treatment by end of the trial. All patients gave written informed consent prior to their participation in the study. The RCT was registered retrospectively on 04th of March 2015 in the German Clinical Trials Registry under the registration ID "DRKS00007649" (see
Additional file 1: Trial registration), and was approved by the local Ethics Committee (Reference No. 15081997) of the Hannover Medical School (MHH), Hanover, Germany (see Additional file 2: Study history and disclaimer).

\section{Patients}

All patients were kept informed of all study details including the cross-over design. Written informed consent was given by all patients of the RCT. Recruitment and allocation of patients throughout the clinical trial are summarized in Fig. 2. Of 90 patients assessed for eligibility at the Department of Clinical Psychiatry and Psychotherapy, $\mathrm{MHH}$, Hanover, Germany, 40 were enrolled. Inclusion criteria were BDV-1 infection and a current depressive episode. Infection variables were determined at the Robert Koch Institute, Berlin, Germany for at least two consecutive time-points prior to study entry (see Additional file 2: Study history and disclaimer). Of 36 patients allocated to intervention, 18 each were randomly assigned to either Group A (amantadine) or Group P (placebo) in period I (weeks 1-7; 6 weeks treatment, 1 week wash-out) of the trial. Amantadine sulphate (totally $200 \mathrm{mg}$ ) was given orally and twice daily (100 mg/morning and $100 \mathrm{mg} /$ midday). Two patients of Group A and one patient of Group P discontinued intervention in period I. For the cross-over period II (weeks 8-14), 16 remaining patients of Group A received placebo and 17 remaining patients of Group $\mathrm{P}$ received amantadine (totally 33 patients). One patient of either group discontinued intervention in period II, leaving 15 patients of Group A and 16 patients of Group P, who completed the cross-over treatment (totally $N=31$ ). The post-trial follow-up period of 12 months with optional

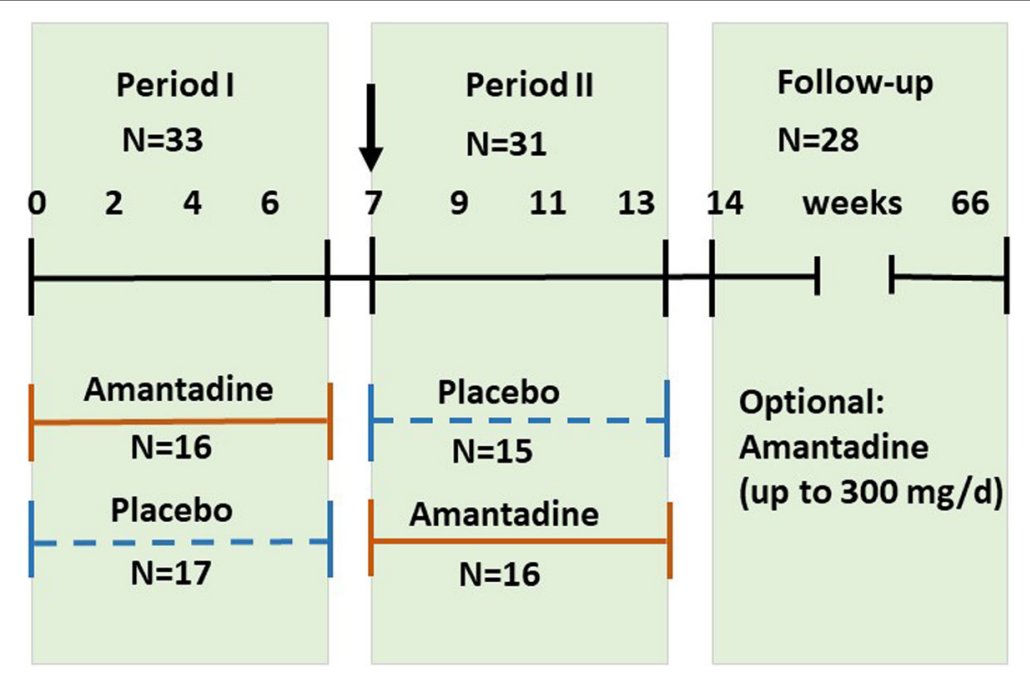

Fig. 1 Study design. The graphic illustrates the timeline of the two treatment periods and the follow-up, as well as the cross-over design of intervention by either amantadine or placebo and vice versa of the study, and indicates the number of patients who finished each period ( $N$ ) 


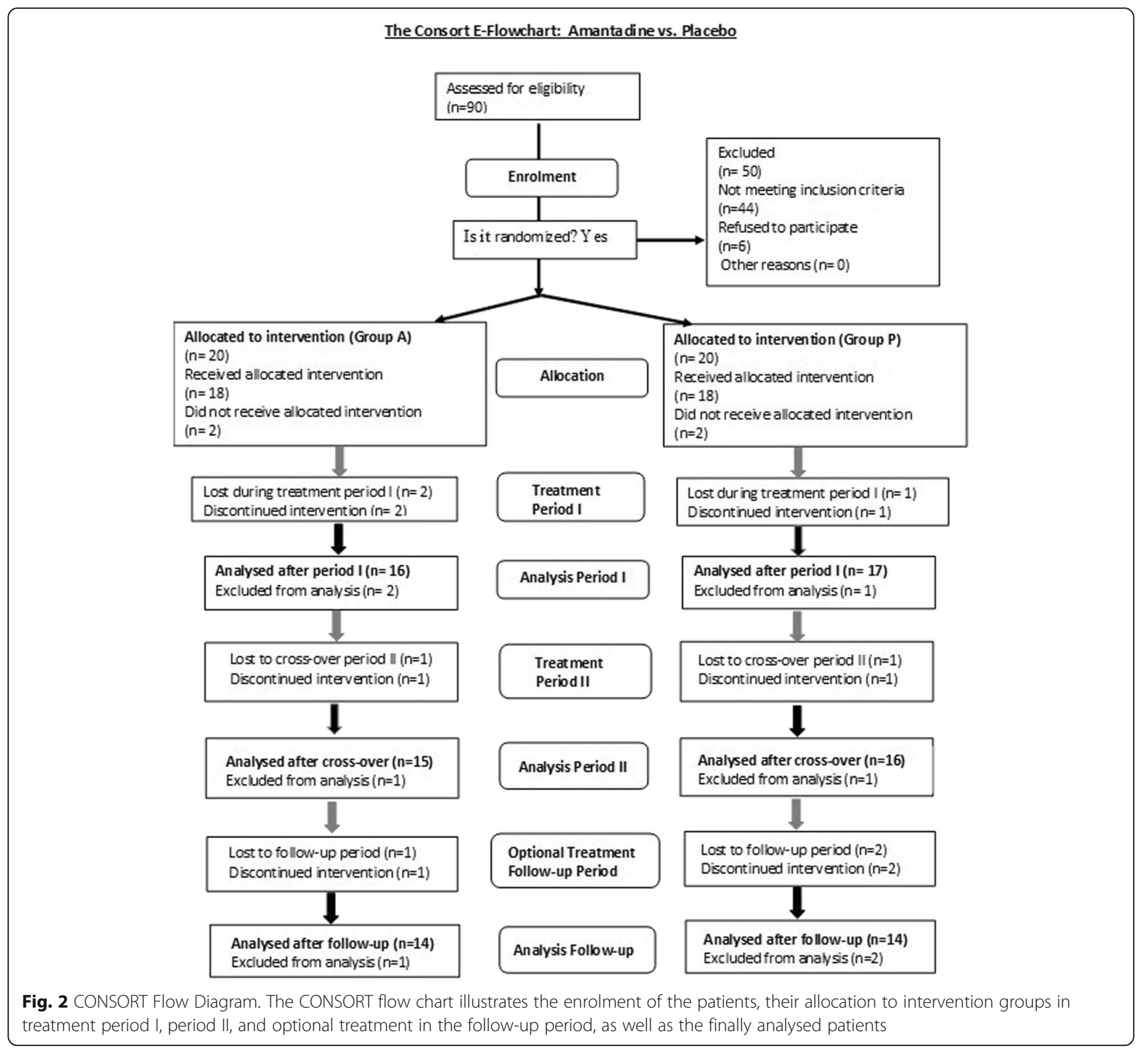

amantadine treatment up to $300 \mathrm{mg} / \mathrm{d}$ was completed by 28 remaining patients. A dosage adaptation was offered to adjust to $2-4 \mathrm{mg}$ amantadine daily per kilogram $(\mathrm{kg})$ body weight $(\mathrm{BW})$ reflecting mean daily dose ranges of amantadine of $100-200 \mathrm{mg}$ for patients between $50 \mathrm{~kg}$ and $75 \mathrm{~kg} \mathrm{BW}$ and $150-300 \mathrm{mg}$ for patients with more than $75 \mathrm{~kg}$ BW.

Of the 33 patients finishing the first treatment period (7 weeks), $60 \%(N=20)$ were diagnosed as having recurrent (at least one former affective episode documented) major depression (MD), and $40 \%(N=13)$ as having bipolar depression (BD; bipolar I, $N=7$; bipolar II, $N=6$ ), according to DSM-IV [43], since a mean of $15.1 \pm 10$ years. They were of either sex and between 33 and 69 years old. Severity of depression at baseline according to
HAMD [42] was 12-20 points for outpatients and 1530 points for inpatients. Severity differences were unrelated to patients' age, sex, socioeconomic status, and educational years. Out- and inpatients were randomly assigned to either Group A (amantadine) or Group P (placebo).

Exclusion criteria were major organic diseases, a history of intolerance of compounds of PK-Merz ${ }^{\circledR}$ (amantadine sulphate), minor depression, current substance dependence, presence of any central nervous system, neuromuscular or uncontrolled systemic and other severe medical disorders, psychotic features or serious suicidal risks, and pregnancy. Exclusion of organic diseases were done by routine medical examinations and blood tests. Therapeutic pre-treatment strategies $(\mathrm{N}=20)$ were 
maintained and remained unchanged during the study. An overview on baseline characteristics of study patients is given in Table 1.

\section{Clinical assessments \\ Definition of outcomes}

The Primary Outcome was defined as change of depressive symptoms measured by total HAMD (21 items) [42] after 6 weeks of treatment plus 1 week wash out, comparing amantadine and placebo groups. Clinical endpoints were defined as reduction of pre-treatment HAMD scores of $\geq 25 \%$ by week 7 (end of period I).
Additionally and in parallel, the change of BDV-1 activity was studied (see Infection assessments). According to the trial protocol, the cross-over therapy switch after 7 weeks was designed for ethical reasons to ensure that all patients benefit from the putative efficacy of amantadine. A statistical in-depth analysis of cross-over results was not taken under consideration, because carry-over effects of the first treatment period could not be excluded despite the 1 week wash out.

The Secondary Outcomes were defined as changes in additional standardized depression inventories after 6 weeks of treatment plus 1 week wash out, comparing

Table 1 Baseline characteristics of patients

\begin{tabular}{|c|c|c|c|c|}
\hline Characteristic & $\begin{array}{l}\text { Amantadine } \\
(N=16)\end{array}$ & $\begin{array}{l}\text { Placebo } \\
(N=17)\end{array}$ & $\begin{array}{l}\text { Total } \\
(N=33)\end{array}$ & P-value \\
\hline Age, mean $\pm S D$, years & $50.69 \pm 10.18$ & $54.67 \pm 9.63$ & $52.79 \pm 9.94$ & 0.154 \\
\hline Female, N (\%) & $12(75)$ & $8(47.1)$ & 21 & \\
\hline > 1 year of college, $\mathrm{N}(\%)$ & $14(87.5)$ & $15(88.2)$ & 29 & \\
\hline Recurrent major depression & $10(62.5)$ & $10(58.8)$ & 20 & \\
\hline \multicolumn{5}{|l|}{ Bipolar depression, N (\%) } \\
\hline Bipolar I & $3(18.75)$ & $4(23.5)$ & 7 & \\
\hline Bipolar \| & $3(18.75)$ & $3(17.6)$ & 6 & \\
\hline Mean number of depressive episodes per year (past 3 years prior to current episode) & $1.0 \pm 1.1$ & $1.04 \pm 1.2$ & $1.02 \pm 1.1$ & 0.904 \\
\hline Mean duration of depressive episodes (weeks) (past 3 years prior to current episode) & $25.6 \pm 21$ & $23.7 \pm 18$ & $24.6 \pm 19$ & 0.781 \\
\hline Duration of illness (years) & $12.4 \pm 9$ & $17.6 \pm 11$ & $15.1 \pm 10$ & 0.135 \\
\hline Patients with antidepressant or mood stabilizing co-medication, N (\%) & $12(75)$ & $8(47.1)$ & 20 & \\
\hline Amitriptyline & 3 & 3 & 6 & \\
\hline Doxepin & 1 & 1 & 2 & \\
\hline Mirtazapine & 1 & & 1 & \\
\hline Clomipramine & 1 & & 1 & \\
\hline Trimipramine & 1 & & 1 & \\
\hline Tranylcypromine & 1 & & 1 & \\
\hline Moclobemide & 1 & & 1 & \\
\hline Sertraline & & 2 & 2 & \\
\hline Paroxetine & 1 & 1 & 2 & \\
\hline Dibenzepine & 1 & & 1 & \\
\hline Maprotiline & & 1 & 1 & \\
\hline Lithium & 2 & 2 & 4 & \\
\hline Carbamazepine & 2 & 2 & 4 & \\
\hline Valproate & 1 & & 1 & \\
\hline Lorazepam & 3 & 1 & 4 & \\
\hline Alprazolam & 1 & & 1 & \\
\hline Zolpidem & & 1 & 1 & \\
\hline Sulpirid & 1 & & 1 & \\
\hline L-Thyroxin & & 2 & 2 & \\
\hline Dihydroergotamine & 1 & & 1 & \\
\hline Estrogenes & 1 & 1 & 2 & \\
\hline
\end{tabular}


amantadine and placebo groups. The depression related well-being status was measured by the mental health self-rating score „Befindlichkeitsskala nach von Zerssen "(BfS) [44]. HAMD and BfS rating scales were evaluated at baseline and weeks 2, 4, 7, 9, 11, 13, 14. Further symptoms, e.g. somatization, were rated on the self-rating symptoms check-list (SCL-90R) [45] at baseline and weeks $2,7,9,14$.

\section{Evaluation measures (clinical outcomes)}

Assessment and documentation of depression- related and other symptoms were made blind with regard to treatment arms (amantadine or placebo). After finishing periods I and II the patients were offered to be followedup in an open setting with optional amantadine treatment for at least 12 months in between which all clinical and infection variables were analysed again. The clinical course (HAMD, 21-items) in each treatment period was analysed through one measure for baseline and 12month follow-up investigation, and the maximum (MAX) and mean (MEAN) of two different measures during the first (week 4 and 7), and the second treatment period (week 11 and 14).

\section{Infection assessments \\ Detection methods}

BDV-1 infection was monitored by quantitative determination of specific circulating immune complexes (CIC), antigens (PAG), and antibodies (AB) in blood plasma using a modular enzyme-immune-assay (EIA) technique [41]. Test specificity based on two monoclonal antibodies (mABs) (anti-N W1; anti-P Kfu2) [46] had been validated through epitope mapping, and test sensitivity by recombinant proteins [47]. The EIA-systems were applied throughout the study as for the superiority of antigen/antibody-related assays over nucleic acidrelated techniques. All laboratory investigations were made blind for any information about treatment arms and/or clinical outcomes in that samples were coded in 5-digit numbers upon receipt. Initial sample processing of citrated blood samples included separation into plasma and PBMCs by density gradient centrifugation (Ficoll-Paque), coding prior to any assay, and storage at $-20^{\circ} \mathrm{C}$ and $-80^{\circ} \mathrm{C}$, respectively. Initial handling and assay performance was done by different laboratory personnel. Raw assay data collection and formal verification (independent control samples) were solely made on coded samples, blinded to any clinical information.

Antigens ( $\mathrm{N}$ - and P-protein; N/P heterodimers) were basically determined from plasma (PAG) as predominant source, using an initial dilution of 1:2. Antibody bound antigen (CIC) was determined from plasma using an initial dilution of 1:20, and antibodies (AB) using an initial dilution of 1:100 in respective EIAs.
Antibodies were additionally determined by an indirect immunofluorescence test (IFT) at initial dilutions of 1 : 10 , using a double-stain technique as described previously [48]. All EIAs used the same standardized cut off value of $\leq 0.1$. The cut off has been calculated as mean value of negative samples plus three standard deviations.

\section{Conducted tests}

A total of $\mathrm{N}=2947$ single-item tests were conducted, covering the above assays and 35 study patients (including two drop-outs). A mean number of 16.8 samples per patient were examined over time, adding up to a mean of totally 588 tests in each assay.

\section{Evaluation measures (infection)}

Infection variables were assessed without knowledge of the clinical outcome. CIC, antigens and antibodies were analysed by maximum (MAX) and mean (MEAN) measures of each variable as well as of summated measures. Assessments included at least two pre-treatment scores at baseline, at week 4 and 7 for the first, and week 11 and 14 for the second treatment period, respectively. For the 12-month follow-up investigation only one set of single and summated BDV measures was available.

\section{In vitro assays}

We applied two different methods to quantitatively determine the antiviral efficacy of amantadine in vitro which were in part described previously $[6,15]$.

\section{In vitro prevention of infection}

These assays used uninfected young rabbit spleen (YRS) cells grown in 24-well tissue culture plates according to standard procedures [46]. Amantadine sulphate $(4 \mathrm{mg} /$ $\mathrm{mL}$ ) was dissolved in ethanol, diluted 1:10 in phosphatebuffered saline (PBS, pH 7.2), and applied in geometric dilution steps (base 2) to YRS cells, starting with $40 \mu \mathrm{g} /$ $\mathrm{mL}$ for $1 \mathrm{~h}$ at $37^{\circ} \mathrm{C}$. Thereafter, cells were infected with 100 focus forming units (FFU) of human BDV strain Hu-H1 (passage 55) [20]. After $2 \mathrm{~h}$ at $37^{\circ} \mathrm{C}$ cells were washed with medium and kept for 6 days under standard conditions $\left(37^{\circ} \mathrm{C}, 5 \% \mathrm{CO}_{2}, 100 \%\right.$ humidity). Foci were determined for each culture by standard cell-ELISA as described previously [46]. Buffer control indicated 100\% infection ( $0 \%$ prevention of infection). Exactly the same protocol and virus strain were used to conduct the parallel assay with memantine, here starting with an initial drug concentration of $200 \mu \mathrm{g} / \mathrm{mL}$. The efficacy of amantadine and memantine to prevent BDV-1 infection was compared according to the $50 \%$ infection-inhibitory dose (ID 50 ). 


\section{In vitro inhibition of replication}

These longitudinal assays used human oligodendroglial (OL) cells persistently infected with either the above human strain BDV Hu-H1 [20] or the non-natural laboratory adapted animal strain $\mathrm{V}$ [14]. For a treatment period of 60 days, cells were split every 3 days and each culture was kept at different amantadine doses between $1.2 \mu \mathrm{g} / \mathrm{mL}$ down to zero. At each passage comprising 15 time points within the 2-months period, virus titres were determined by titrating suspensions of $5 \times 10^{7}$ ultrasonicated OL cells on YRS cells as described earlier [20]. Virus infectious units were expressed as focus forming units (FFU) per $\mathrm{mL}$ as already mentioned, providing that one infectious unit causes one focus (20-50 antigencarrying cells) which can be visualized by a focus immunoassay (cell ELISA) [46]. The efficacy of amantadine to inhibit replication was analysed in accord to dose and time, comparing two strains of different origin and biology $[22,23]$.

\section{Statistical analysis \\ Clinical outcomes}

According to the primary and secondary outcomes (change of depressive symptoms) t-tests were applied to compare HAMD-scores [42] of both treatment groups, using the one-sided version at significance level $p \leq 0.05$. Analyses included the differences between pre-treatment scores and scores at week 2, 4, 7, and 9 of the HAMDscore (DHAMD), the single HAMD items (1-21), certain clusters of these items indicating melancholic features ("DENDOG", represented by the HAMD-items 5, $6,7,8,12,16$, and 18) or retardation ("DRETARD", represented by the HAMD-items $1,7,8$, and 18) of the patients, and changes of the mental state self-rating score (BfS) [44]. Analyses were based on above evaluation measures representing the clinical course in each treatment period.

A two-sided paired t-test was applied to compare the frequency and duration of depressive episodes (no manic episode occurred) during the follow-up period with a period of 3 years prior to the current depressive episode.

In addition to statistical differences between treatment groups, the magnitude of these differences, namely the effect size (ES) values (Cohen's d; Hedges's g) [49, 50] were determined [51] for above multi-item and single item scores to evaluate the clinical significance, allowing for comparison with other RCTs.

\section{Infection outcomes}

T-tests using the one-sided version at significance level $p \leq 0.05$ were also applied to analyse inter-assay correlations of infection variables by maximum (MAX) and mean (MEAN) measures of each variable as well as of summated measures at above defined time-points.

\section{Correlation of clinical and infection outcomes}

To determine correlations between initial BDV measures and clinical changes (relative difference of the Hamilton pre-treatment- and 7-week-scores $=$ RDHAMD7) during the first treatment period, a covariance analysis (ANCOVA) with treatment as factor and initial BDV measures as co-variables was performed. The initial BDV measures used were the maximum (MAX) and mean (MEAN) of at least two BDV measures (for BDV variables antigens, antibodies, and CICs) prior to start of the trial.

Patient-related correlations between the clinical course and virus infection variables were investigated across the different treatment periods using a mixed linear model. The mixed model set the clinical course as dependent variable, the patient as random factor, and treatment and infection data as time-dependent factors or covariates, respectively. Statistical analyses on the strength of association within and between clinical and infection variables were done through calculating Pearson's correlation coefficient (r) and Spearman's coefficient of rank correlation (2-tailed) by aid of up-to-date SPSS software, finally completed using version 19.0 (IBM SPSS Statistics for Windows, released 2010).

\section{Results}

This is the first report on the clinical and antiviral efficacy of amantadine in BDV-1 infected depressive patients evaluated in a company-independent RCT and conducted in a placebo-controlled cross-over and double-blind design.

\section{Clinical outcomes \\ Primary response}

The main primary outcome measure and principal clinical objective was defined as the change of the 21item HAMD score between end and beginning of the first 7-weeks period. The differences between the two treatment groups $(\mathrm{A}=$ amantadine, $\mathrm{P}=$ placebo $)$ were summarized in Table 2.

Based on 33 patients ( $N=16$ on amantadine) and clinical endpoints of a HAMD-score reduction of $\geq 25 \%$ as shown in Table 2 , significantly different response rates of $81.3 \%$ for the amantadine (A) and $35.3 \%$ for the placebo $(\mathrm{P})$ group $(p=0.003)$ were obtained by week 7 . This corresponded to an effect size (ES; Cohen's d) [49] of 1.046 which valued the clinical significance to be extraordinarily large. By defining endpoints as HAMD-score reduction of $\geq 50 \%$, the response rates were $43.8 \%$ (A) and $0 \%(\mathrm{P})$. 
Table 2 Primary clinical outcomes

\begin{tabular}{|c|c|c|c|}
\hline Patients $N=33$ & Differences A vs. $P^{a}$ & Patients with Amantadine(A) $N=16$ & Patients with Placebo $(P) N=17$ \\
\hline Response & & 13 & 6 \\
\hline Non-response & & 3 & 11 \\
\hline Response rate (\%) & & $13 / 16=0.8125(81.25 \%)$ & $6 / 17=0.3529(35.29 \%)$ \\
\hline Statistical significance (defined as $p<0.05$ ) & $p=0.003$ & & \\
\hline Absolute response difference & $81.25-35.29=45.96 \%$ & & \\
\hline Relative response (RR) & $81.25 / 35.29=2.302$ & & \\
\hline Odds & & $13 / 3=4.33$ & $6 / 11=0.55$ \\
\hline Odds ratio (OR) & $4.33 / 0.55=7.872$ & & \\
\hline Effect size of difference (expressed as Cohen's $d$ ) & $d=1.0461$ & & \\
\hline Effect size of difference (expressed as Hedges's g) & $g=1.0175$ & & \\
\hline Effect size of association (correlation coefficient $r$ ) & $r=0.463$ & & \\
\hline
\end{tabular}

a Primary outcome defined as changes between pre-treatment scores and scores at week 7 of the HAMD (DHAMD). Clinical endpoint defined as reduction of HAMD $\geq 25 \%$. Time endpoint: 7 weeks

By end of both treatment periods and cross-over, after 14 weeks, the clinical response of all remaining 31 patients was $74.2 \%(23 / 31)$ and $54.8 \%(17 / 31)$, as for above endpoints of $\geq 25 \%$ reduction and $\geq 50 \%$ reduction of the HAMD-score, respectively. Finally, by end of the followup period of 12 months offering optional amantadine treatment, after 66 weeks, the clinical response of the remaining 28 patients reached $82.1 \%(23 / 28)$ and $64.3 \%$ $(18 / 28)$, as for endpoints of $\geq 25 \%$ reduction and $\geq 50 \%$ reduction of the HAMD-score, respectively.

The clinical response of all study periods has also been analysed at the level of individual patients (see Additional file 3: Table S1). Remarkably, amantadine treatment in Period I had a strong impact on the placebo effect in Period II in that $69.2 \%$ (9/13) responder in Period I maintained response under placebo in Period II, adding up to $80.0 \%(12 / 15)$ in whole Group A at week 14. In contrast, as for placebo treatment in Period I (response $35.3 \%$ ), a significantly different responder rate of $68.8 \%(11 / 16)$ was reached after cross-over to amantadine in whole Group P in Period II, at week 14. Previous open trials had revealed similar rates after 12 weeks [7, 8]. Of those patients who were offered optional amantadine treatment for 12 further months, almost all (92.9\%) (13/14) became responder (Group P).

\section{Secondary outcomes and clinical course of treatment}

The efficacy of amantadine vs. placebo treatment was monitored throughout the entire study at week 2 to week 14 from baseline. The clinical course of treatment was detailed for total HAMD-21, eight further single HAMD-items and a self-rating score for well-being (BfS), as well as combined HAMD-clusters indicating melancholic and retardation-related features (DENDOG and DRETARD), respectively (Fig. 3, 4, 5 and 6).

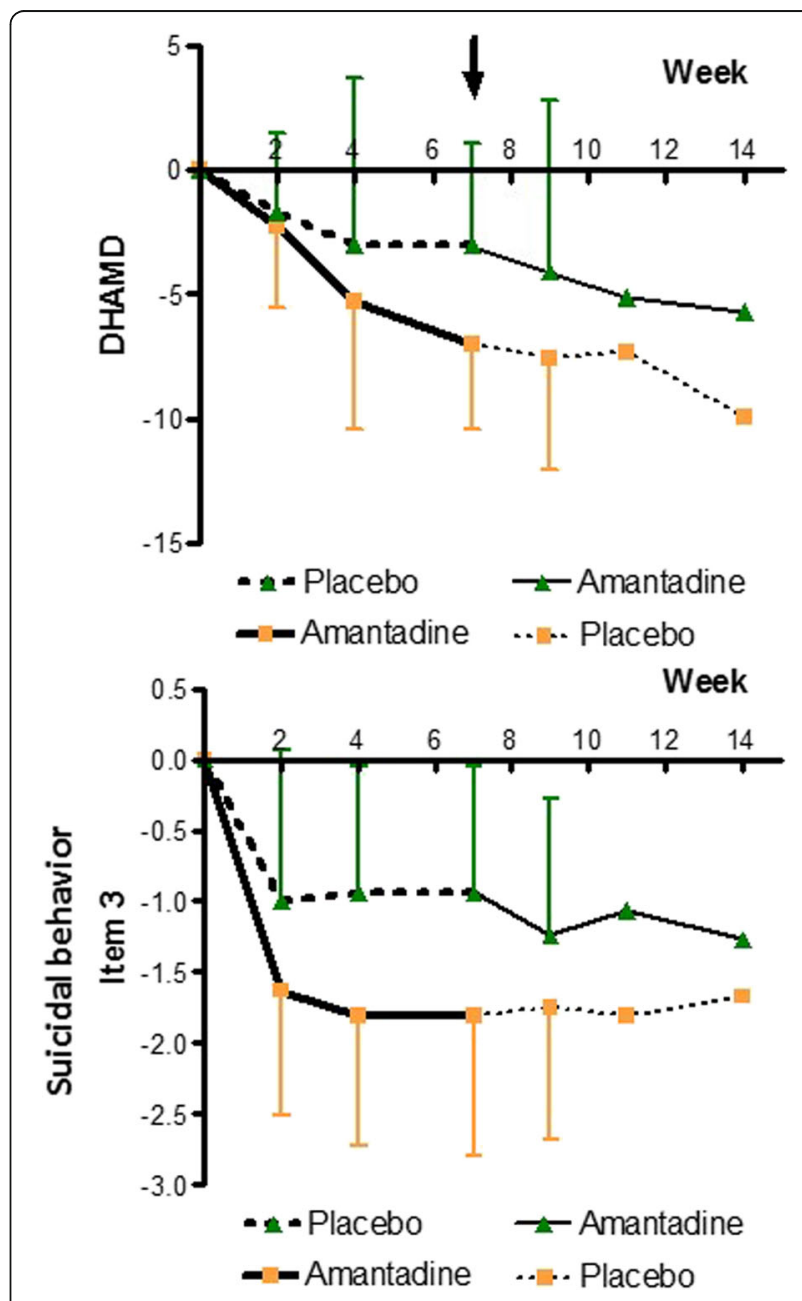

Fig. 3 Course of treatment 1 (HAMD-21 and suicidal behaviour, item 3). At the top: treatment effect of amantadine compared to placebo measured by the difference in total HAMD-score, week 7 marked by an arrow. At the bottom: treatment effect by the difference in HAMD item 3 "suicidal behaviour". For $p$-values and effect size indicators at different time points, see Table 3 and Table 4 


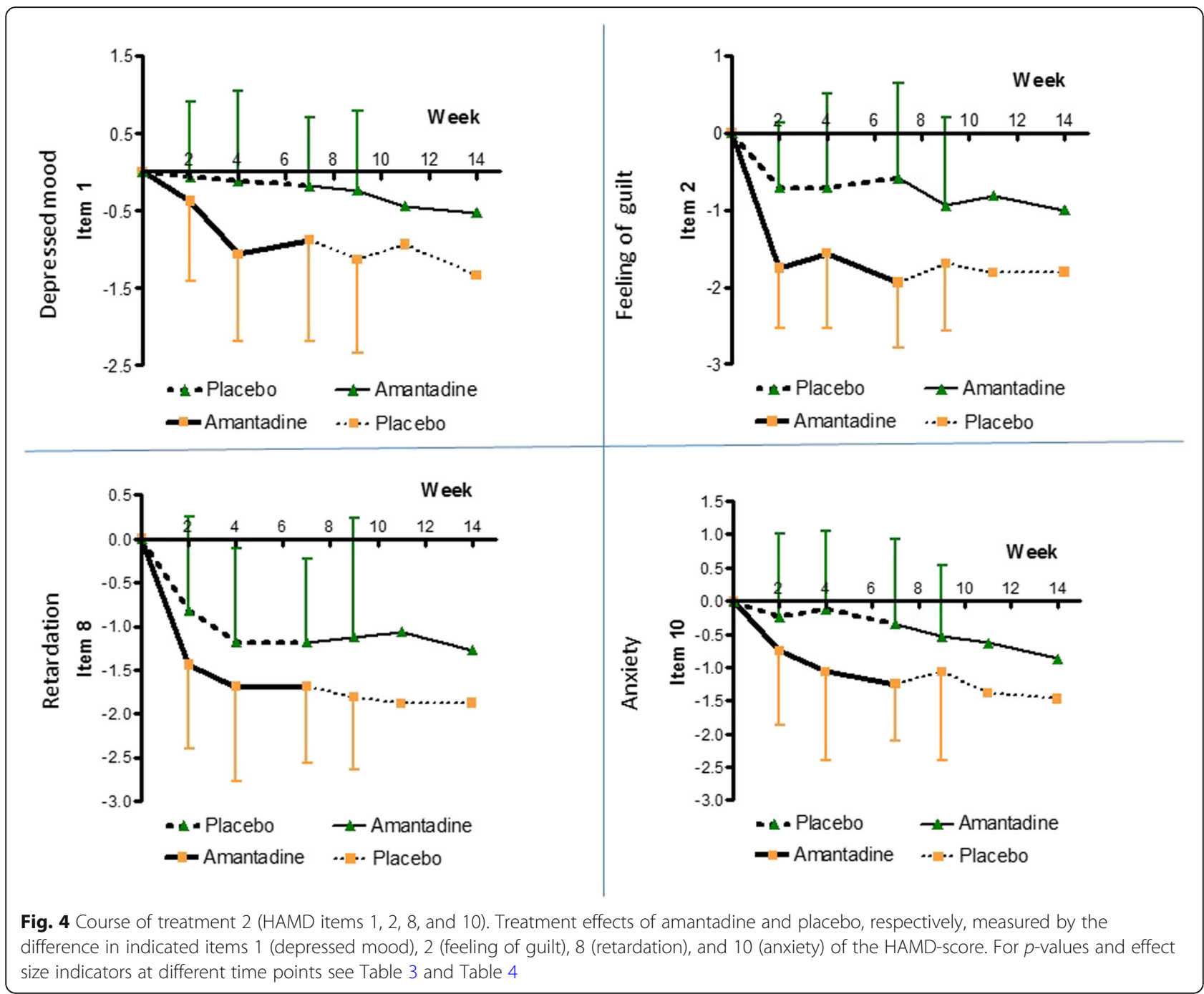

With respect to the main clinical outcome after 7 weeks, single-item score differences between amantadine and placebo groups were calculated according to statistical significance, clinical effect size (ES, d-value), and correlation coefficient levels (Tables 3 and 4).

Notably, as shown in Fig. 3, amantadine significantly reduced "suicidal behaviour" (item 3 ) as early as by 2 weeks of treatment $(p=0.039, \mathrm{~d}=0.662)$, earlier than the total Hamilton score. If this finding holds true in larger RCTs, it could help saving patients' lives by closing a treatment and safety gap reported for SSRIs [4, 52, 53]. Suicidal behaviour dropped continuously during amantadine treatment, given effect size levels (d-values) of 0.97 by 4 weeks up to 1.02 by 7 weeks.

Likewise by 2 weeks, single HAMD items, namely "feeling of guilt" (item 2; $p=0.0005, \mathrm{~d}=1.300$ ) and "retardation" (item $8 ; p=0.048, \mathrm{~d}=0.620$ ), were significantly improved by amantadine (Fig. 4 , Table 3 ). By 4 weeks of treatment, also earlier than the total Hamilton score, single items "depressed mood" (item $1 ; p=0.012$, $\mathrm{d}=0.778$ ), "anxiety" (item $10 ; p=0.019, \mathrm{~d}=0.751$ ), "dayvariations" (item $18 ; p=0.033, \mathrm{~d}=0.682$ ), and the selfrated well-being score $\operatorname{BfS}(p=0.035, \mathrm{~d}=0.653)$ could be significantly improved by amantadine (Fig. 4 and Fig. 5 , Table 3).

The evaluation of combined HAMD clusters representing retardation (DRETARD) and melancholic features (DENDOG) revealed a different time pattern for improvements by amantadine. While the retardation cluster significantly improved as early as by 2 weeks ( $p=$ $0.025, d=0.707$ ) and further throughout the course of treatment, melancholic features improved delayed by 9 weeks ( $p=0.0022, \mathrm{~d}=0.989)$ upon amantadine treatment (Fig. 6, Table 3 and Table 4). Cognitive dysfunction across multiple domains is known as a frequent residual manifestation in depression [54]. Here, we found early 


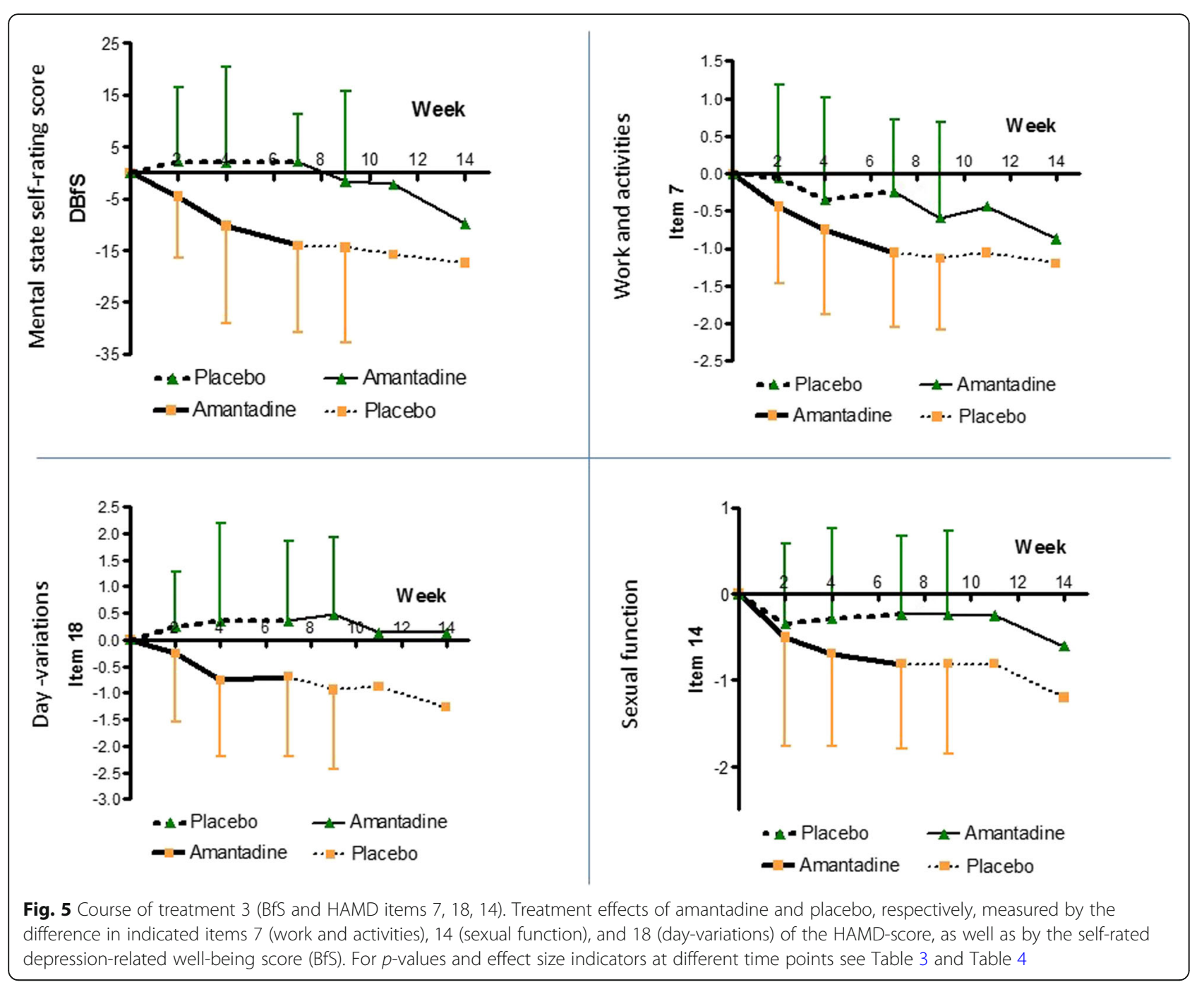

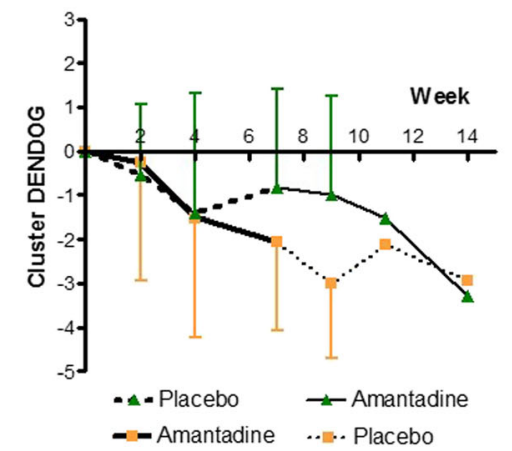

DENDOG $=$ Cluster melancholic features based on differences of HAMD items 5, 6, 7, 8, 12, 16, 18

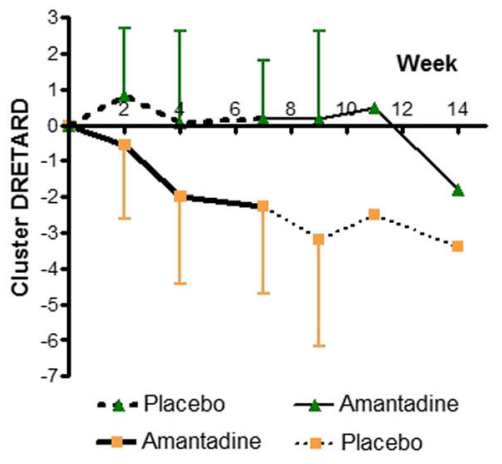

DRETARD $=$ Cluster retardation based on differences of HAMD items 1, 7, 8, 18

Fig. 6 Course of treatment 4 (combined HAMD cluster). Treatment effects of amantadine and placebo, respectively, measured by the difference in combined items of the HAMD-score, clustering for either melancholic (DENDOG) or retardation (DRETARD) features. For $p$-values and effect size indicators at different time points see Table 3 and Table 4 
Table 3 Clinical effect size and significance levels by weeks 2 and 4 from baseline

Table 3a. Clinical effect size and significance levels measures by weeks $\mathbf{2}$ and $\mathbf{4}$ from baseline

\begin{tabular}{|c|c|c|c|c|c|c|c|c|c|}
\hline & & 2 Weeks & & & & 4 Weeks & & & \\
\hline & & $\mathrm{M} \pm \mathrm{SD}$ & $\mathrm{p}$-value & d-value & r-value & $M \pm S D$ & $p$-value & d-value & $r$-value \\
\hline \multirow[t]{2}{*}{ DHAMD } & A & $-2.31 \pm 3.3$ & & \multirow[t]{2}{*}{0.185} & \multirow[t]{2}{*}{0.092} & $-5.31 \pm 5.1$ & & \multirow[t]{2}{*}{0.388} & \multirow[t]{2}{*}{0.190} \\
\hline & $P$ & $-1.71 \pm 3.2$ & & & & $-3 \pm 6.7$ & & & \\
\hline DHAMD1 & A & $-0.38 \pm 1$ & & \multirow[t]{2}{*}{0.440} & \multirow[t]{2}{*}{0.214} & $-1.06 \pm 1.1$ & 0,012 & \multirow[t]{2}{*}{0.778} & \multirow[t]{2}{*}{0.363} \\
\hline $\begin{array}{l}\text { "depressed } \\
\text { mood" }\end{array}$ & $\mathrm{P}$ & $0.06 \pm 1$ & & & & $-0,12 \pm 1.2$ & & & \\
\hline DHAMD2 & A & $-1.75 \pm 0.8$ & \multirow[t]{2}{*}{0.0005} & \multirow[t]{2}{*}{1.300} & \multirow[t]{2}{*}{0.545} & $-1.56 \pm 1$ & 0.017 & \multirow[t]{2}{*}{0.769} & \multirow[t]{2}{*}{0.359} \\
\hline $\begin{array}{l}\text { "feeling of } \\
\text { guilt" }\end{array}$ & $\mathrm{P}$ & $-0.71 \pm 0.8$ & & & & $-0.71 \pm 1.2$ & & & \\
\hline DHAMD3 & A & $-1.63 \pm 0.9$ & \multirow[t]{2}{*}{0.039} & \multirow[t]{2}{*}{0.662} & \multirow[t]{2}{*}{0.314} & $-1.81 \pm 0.9$ & 0.005 & \multirow[t]{2}{*}{0.967} & \multirow[t]{2}{*}{0.435} \\
\hline "suicide" & $P$ & $-1 \pm 1$ & & & & $-0.94 \pm 0.9$ & & & \\
\hline DHAMD7 & A & $-0.44 \pm 1$ & & \multirow[t]{2}{*}{0.344} & \multirow[t]{2}{*}{0.169} & $-0.75 \pm 1.1$ & & \multirow[t]{2}{*}{0.318} & \multirow[t]{2}{*}{0.157} \\
\hline $\begin{array}{l}\text { "work and } \\
\text { activities" }\end{array}$ & $\mathrm{P}$ & $-0.06 \pm 1.2$ & & & & $-0.35 \pm 1.4$ & & & \\
\hline DHAMD8 & A & $-1.44 \pm 1$ & \multirow[t]{2}{*}{0.048} & \multirow[t]{2}{*}{0.620} & \multirow[t]{2}{*}{0.296} & $-1.69 \pm 1.1$ & $(0.092)$ & \multirow[t]{2}{*}{0.464} & \multirow[t]{2}{*}{0.226} \\
\hline "retardation" & $\mathrm{P}$ & $-0.82 \pm 1$ & & & & $-1.18 \pm 1.1$ & & & \\
\hline DHAMD10 & A & $-0.75 \pm 1.1$ & & 0.424 & 0.207 & $-1.06 \pm 1.3$ & 0.019 & 0.751 & 0.352 \\
\hline $\begin{array}{l}\text { "anxiety } \\
\text { (psychic)" }\end{array}$ & $\mathrm{P}$ & $-0.24 \pm 1.3$ & & & & $-0.12 \pm 1.2$ & & & \\
\hline DHAMD14 & A & $-0.5 \pm 1.3$ & & 0.134 & 0.067 & $-0.69 \pm 1.1$ & & 0.381 & 0.187 \\
\hline $\begin{array}{l}\text { "sexual } \\
\text { function" }\end{array}$ & $P$ & $-0.35 \pm 0.9$ & & & & $-0.29 \pm 1$ & & & \\
\hline DHAMD18 & A & $-0.25 \pm 1.3$ & & 0.422 & 0.206 & $-0.75 \pm 1.4$ & 0.033 & 0.682 & 0.322 \\
\hline $\begin{array}{l}\text { "day- } \\
\text { variations" }\end{array}$ & $\mathrm{P}$ & $0.24 \pm 1$ & & & & $0.35 \pm 1.8$ & & & \\
\hline DENDOG & A & $-0.25 \pm 2.7$ & & 0.126 & 0.062 & $-1.5 \pm 2.7$ & & 0.033 & 0.017 \\
\hline & $\mathrm{P}$ & $-0.53 \pm 1.6$ & & & & $-1.41 \pm 2.7$ & & & \\
\hline DRETARD & A & $-0.56 \pm 2$ & 0.025 & 0.707 & 0.333 & $-2 \pm 2.4$ & 0.012 & 0.840 & 0.387 \\
\hline & $\mathrm{P}$ & $0.82 \pm 1.9$ & & & & $0.06 \pm 2.5$ & & & \\
\hline DBfS & A & $-4.63 \pm 12$ & $(0.074)$ & 0.518 & 0.250 & $-10.25 \pm 18.8$ & 0.035 & 0.653 & 0.310 \\
\hline & $P$ & $2.18 \pm 14.2$ & & & & $1.94 \pm 18.5$ & & & \\
\hline $\begin{array}{l}\text { Total mean d- } \\
\text { value }\end{array}$ & & & & 0.822 & & & & 0.777 & \\
\hline DHAMD & Differe & ore of the $\mathrm{H}$ & ilton rati & cale of $d e$ & ssion (HA & 1-D; 21 items) & Numbers $r$ & $r$ to singl & $\mathrm{ms}$ \\
\hline DENDOG & Differe & ore of the a & ed items & $7,8,12,1$ & 8 , represe & ting the mela & cholicfea & & \\
\hline DRETARD & Differe & ore of the a & ed items & 8,18 , rep & enting fe & ures of retard & ion & & \\
\hline DBfS & Differe & ore of the " & findlichk & kala nach & Zerssen & (self-rating sc & & & \\
\hline$A=$ Amantad & line trea & t, $\mathrm{P}=\mathrm{Placeb}$ & p-values & tatistical & ificance $b$ & sed on one-si & ed t-test & & \\
\hline
\end{tabular}

and sustained improvement of cognitive impairment by amantadine (DRETARD cluster) providing a remarkable difference to orthodox treatment.

At the end of treatment period I (week 7), amantadine was significantly superior to placebo across all measured single items of HAMD. The pronounced clinical significance of the drug was not only indicated through the large d-value of the total DHAMD-21 difference to placebo $(\mathrm{d}=1.05)$, but also for mean $\mathrm{d}$-values covering depressed mood, feeling of guilt, suicide, work and activities, psychic anxiety, sexual function, and day-variations (mean $d=0.83$ ). The subjective benefit in the amantadine group was best reflected by one of the highest $d$ values $(\mathrm{d}=1.22)$ in the self-rating score for well-being (DBfS). The cumulative effect size development is additionally provided (Additional file 4: Figure S1). 
Table 4 Clinical effect size and significance levels by weeks 7 and 9 from baseline

Table 3b. Clinical effect size and significance levels by weeks 7 and 9 from baseline

\begin{tabular}{|c|c|c|c|c|c|c|c|c|c|}
\hline & & 7 Weeks & & & & 9 Weeks & & & \\
\hline & & $\mathrm{M} \pm \mathrm{SD}$ & $\mathrm{p}$-value & d-value & r-value & $\mathrm{M} \pm \mathrm{SD}$ & $\mathrm{p}$-value & d-value & r-value \\
\hline DHAMD & A & $-7 \pm 3.4$ & 0.003 & 1.046 & 0.463 & $-7.56 \pm 4.3$ & & 0.598 & 0.287 \\
\hline DHAMD1 & A & $-0.88 \pm 1.3$ & 0.041 & 0.626 & 0.299 & $-1.73 \pm 1.2$ & 0.015 & 1.349 & 0.559 \\
\hline $\begin{array}{l}\text { "depressed } \\
\text { mood" }\end{array}$ & $\mathrm{P}$ & $-0.18 \pm 0.9$ & & & & $-0.24 \pm 1$ & & & \\
\hline $\begin{array}{l}\text { "feeling of } \\
\text { guilt" }\end{array}$ & $\mathrm{P}$ & $-0.59 \pm 1.2$ & & & & $-0.94 \pm 1.1$ & & & \\
\hline DHAMD3 & A & $-1.81 \pm 0.8$ & 0.0035 & 1.022 & 0.455 & $-1.75 \pm 0.9$ & $(0.066)$ & 0.536 & 0.259 \\
\hline "suicide" & $\mathrm{P}$ & $-0.94 \pm 0.9$ & & & & $-1.24 \pm 1$ & & & \\
\hline DHAMD7 & A & $-1.06 \pm 1$ & 0.011 & 0.820 & 0.379 & $-1.13 \pm 1$ & $(0.091)$ & 0.466 & 0.227 \\
\hline $\begin{array}{l}\text { "work and } \\
\text { activities" }\end{array}$ & $P$ & $-0.24 \pm 1$ & & & & $-0.59 \pm 1.3$ & & & \\
\hline "retardation" & $\mathrm{P}$ & $-1.18 \pm 1$ & & & & $-1.12 \pm 1.4$ & & & \\
\hline DHAMD10 & A & $-1.25 \pm 0.9$ & 0.013 & 0.805 & 0.373 & $-1.06 \pm 1.3$ & & 0.440 & 0.215 \\
\hline $\begin{array}{l}\text { "anxiety } \\
\text { (psychic)" }\end{array}$ & $\mathrm{P}$ & $-0.35 \pm 1.3$ & & & & $-0.53 \pm 1.1$ & & & \\
\hline DHAMD14 & A & $-0.81 \pm 1$ & 0,044 & 0.599 & 0.287 & $-0.81 \pm 1$ & $(0.055)$ & 0.570 & 0.274 \\
\hline $\begin{array}{l}\text { "sexual } \\
\text { function" }\end{array}$ & $P$ & $-0.24 \pm 0.9$ & & & & $-0.24 \pm 1$ & & & \\
\hline DHAMD18 & A & $-0.69 \pm 1.5$ & 0,028 & 0.693 & 0.327 & $-0.94 \pm 1.5$ & 0.005 & 0.940 & 0.425 \\
\hline $\begin{array}{l}\text { "day- } \\
\text { variations" }\end{array}$ & $P$ & $0.35 \pm 1.5$ & & & & $0.47 \pm 1.5$ & & & \\
\hline \multirow[t]{2}{*}{ DENDOG } & A & $-2.06 \pm 2$ & $(0.053)$ & 0.590 & 0.283 & $-3 \pm 1.7$ & 0.0022 & 0.989 & 0.443 \\
\hline & $\mathrm{P}$ & $-0.82 \pm 2.2$ & & & & $-1 \pm 2.3$ & & & \\
\hline \multirow[t]{2}{*}{ DRETARD } & A & $-2.25 \pm 2.5$ & 0.001 & 1.157 & 0.501 & $-3.12 \pm 3$ & 0.0015 & 1.065 & 0.470 \\
\hline & $\mathrm{P}$ & $0.18 \pm 1.6$ & & & & $-0.18 \pm 2.5$ & & & \\
\hline $\begin{array}{l}\text { Total mean d- } \\
\text { value }\end{array}$ & & & & 0.926 & & & & 1.029 & \\
\hline $\begin{array}{l}\text { DHAMD } \\
\text { single item } \\
\text { mean d-value }\end{array}$ & & & & 0.834 & & & & & \\
\hline DHAMD & \multicolumn{9}{|c|}{ Difference score of the Hamilton rating scale of depression (HAM-D; 21 items). Numbers refer to single items } \\
\hline DENDOG & \multicolumn{8}{|c|}{ Difference score of the added items $5,6,7,8,12,16,18$, representing the melancholic features } & \\
\hline DRETARD & \multicolumn{9}{|c|}{ Difference score of the added items $1,7,8,18$, representing features of retardation } \\
\hline DBfS & \multicolumn{9}{|c|}{ Difference score of the "Befindlichkeitsskala nach von Zerssen" (self-rating scale) } \\
\hline \multicolumn{10}{|c|}{$A=$ Amantadine treatment, $P=P l a c e b o ; p$-values for statistical significance based on one-sided t-test } \\
\hline Effect size me & leasures & leen $A$ and $P$ - & roups bas & on size of & rences & nen's d-valu & ) and size & ssociati & values) \\
\hline
\end{tabular}

\section{Safety}

Amantadine at a daily oral dose of $200 \mathrm{mg}$ was very well tolerated confirming previous open trials [6-8]. The treatment emergent adverse events (TEAEs) during the course of treatment periods were evaluated in Table 5 . Reported single adverse events were further detailed (Additional file 5: Table S2).

Neither serious adverse events (SAEs) nor significant differences between amantadine and placebo periods were observed. No patient discontinued the treatment due to an adverse event (AE). Notably, none of severe side-effects, such as psychotic symptoms, severe anticholinergic effects or restlessness, and sleeplessness, were reported. Those events, however, had been solely described in the context of intravenous application of amantadine in patients with Parkinson's disease.

Furthermore, the symptoms-check-list SCL-90R [45], which was used to screen especially for possible somatic symptoms, did not disclose any major differences of the 
Table 5 Treatment emergent adverse events (TEAEs)

\begin{tabular}{|c|c|c|c|}
\hline Patients $N=32$ & Differences A vs. P & Patients with Amantadine (A) $N=33^{\mathrm{a}}$ & Patients with Placebo (P) $N=33^{\mathrm{a}}$ \\
\hline Side effects & & 15 & 11 \\
\hline No side effects & & 18 & 22 \\
\hline Side effect rate (\%) & Non-significant difference & $15 / 33=0.454(45.4 \%)$ & $11 / 32=0.333(33.3 \%)$ \\
\hline Absolute side effect difference & $45.4-33.3 \%=12.1 \%$ & & \\
\hline Relative risk (RR) & $45.4 / 33.3=1.363$ & & \\
\hline Odds & & $15 / 18=0.83$ & $11 / 22=0.50$ \\
\hline Odds ratio (OR) & $0.83 / 0.5=1.66$ & & \\
\hline
\end{tabular}
cross - over treatment

global severity index (GSI) and of eight out of nine subscales. Only the subscale "interpersonal sensitivity" demonstrated a significant difference between the groups $(p=0.033)$, however, related to a reduction of symptoms in the amantadine group (two-sided t-test).

\section{Sustainability (12-months follow-up)}

Besides the above remarkable short-term antidepressant efficacy of amantadine, we could demonstrate sustainability. For the remaining 28 patients who were offered optional post-study amantadine treatment and agreed to a follow-up examination 12 months after end of study, the frequency of episodes was reduced from $1.97 \pm 1.6$ episodes per year before to $1.0 \pm 1.0$ episode per year after the two treatment periods $(\mathrm{T}=3.525 ; p<0.002)$. Likewise, the duration of episodes was reduced from $22.97 \pm 19.4$ weeks per episode before to $13.07 \pm 16.8$ weeks per episode after the two treatment periods $(\mathrm{T}=$ 4.197; $p<0.001)$. In parallel, the long-term 12-months post-study clinical benefit was significantly correlated with dropped cumulative infection measures (CIC + PAG $+\mathrm{AB}$ ) over time $(p<0.001)$ (see below).

\section{Infection outcomes}

Active BDV-1 infection relates to proteins (antigen in plasma; PAG), host immune response (antibodies; $\mathrm{AB}$ ) and circulating immune complexes (CIC), all of which are dynamically interrelated [41].

Table 6 Correlation of pre-treatment BDV infection variables

\begin{tabular}{|c|c|c|c|c|c|c|}
\hline & & & $A B$ & & $\mathrm{ClC}$ & \\
\hline \multirow[t]{5}{*}{$\overline{\mathrm{PAG}}$} & & & MAX & MEAN & MAX & $\overline{\text { MEAN }}$ \\
\hline & MAX & $r$ & .523 & .618 & .766 & .775 \\
\hline & & $p$ & .002 & .000 & .000 & .000 \\
\hline & MEAN & $r$ & .515 & .625 & .739 & .761 \\
\hline & & $p$ & .002 & .000 & .000 & .000 \\
\hline
\end{tabular}

Correlation between maximum (MAX) and mean (MEAN) values of initial pretreatment $\mathrm{BDV}$ infection measures (PAG antigen; $\mathrm{AB}$ antibodies; $\mathrm{CIC}$ circulating immune complexes).

\section{Correlation of pre-treatment infection variables}

We found strong significant correlations between MAX and MEAN initial amounts of $\mathrm{CIC}$ and $\mathrm{AB}$ with antigen (PAG) values (Table 6). No correlation was found between $\mathrm{CIC}$ and $\mathrm{AB}$ values which may account for the fact that CIC levels are primarily antigen- rather than antibody-driven.

\section{Correlation of infection and clinical variables}

Considering the abundance of clinical and assay results, a mixed model was applied with the clinical course as dependent variable, the patient as random factor, and treatment and infection variables data as timedependent covariates, respectively. The data analysis focused on the first treatment period of 7 weeks which was defined as main clinical outcome. An overview on results of in-depth statistical calculations within and between infection variables and clinical outcome are provided in Table 7. Patients' data of either amantadine or placebo groups were analysed together to provide sufficient statistical power. According to the high clinical effect size of amantadine over placebo, correlations could be mainly assigned to the amantadine group which displayed a clearly more pronounced decrease of infection variables.

Within infection variables, MAX and MEAN pretreatment levels of antigen and CIC correlated significantly with antibody reduction in the first treatment period (MAXPAG $r=-.598 ; p=0.001$, MEANPAG $r=$ $-.581 ; \quad p=0.002 ; \quad$ MAXCIC $r=-.417 ; \quad p=0.034$, MEANCIC $r=-.420 ; p=0.033)$. The higher the initial plasma levels of virus antigen-related variables (PAG and $\mathrm{CIC}$ ), the more pronounced was the $\mathrm{AB}$ reduction in this time period (Table 7; DAB18).

Most remarkable correlations were found between pre-treatment infection variables and favourable clinical outcomes. High initial amounts of antibodies were predictive of pronounced clinical improvement defined as relative HAMD change between baseline (pre-treatment) and week 7 (RDHAMD7) (MAXAB $r=-.561 ; p=0.001$, and MEANAB $r=-.495 ; p=0.003)$. A strong predictive 
Table 7 Correlation between infection and clinical variables

\begin{tabular}{|c|c|c|c|c|c|c|c|c|c|c|c|}
\hline & & DAB18 & DCIC18 & DHAMD7 & RDHAMD7 & MAXAB & MEANAB & MAXCIC & MEANCIC & MAXPAG & MEANPAG \\
\hline \multirow[t]{3}{*}{ DAB18 } & \begin{tabular}{c|} 
Pears on \\
Correlation
\end{tabular} & & & & .450 & & & -.417 & -.420 & -.598 & -581 \\
\hline & Sig. (2-tailed) & & & & .021 & & & .034 & .033 & .001 & .002 \\
\hline & $\mathrm{N}$ & & & & 26 & & & 26 & 26 & 26 & 26 \\
\hline \multirow[t]{3}{*}{ DCIC18 } & $\begin{array}{c}\text { Pears on } \\
\text { Correlation }\end{array}$ & & & & & & & -.399 & -.407 & & \\
\hline & Sig. (2-tailed) & & & & & & & .022 & .019 & & \\
\hline & $\mathrm{N}$ & & & & & & & 33 & 33 & & \\
\hline \multirow[t]{3}{*}{ DHAMD7 } & $\begin{array}{c}\text { Pears on } \\
\text { Correlation }\end{array}$ & & & & & & & & & & \\
\hline & Sig. (2-tailed) & & & & & & & & & & \\
\hline & $\mathrm{N}$ & & & & & & & & & & \\
\hline \multirow[t]{3}{*}{ RDHAMD7 } & $\begin{array}{c}\text { Pears on } \\
\text { Correlation }\end{array}$ & .450 & & & & & & & & -.387 & -.386 \\
\hline & Sig. (2-tailed) & .021 & & & & & & & & .026 & .027 \\
\hline & $\mathrm{N}$ & 26 & & & & & & & & 33 & 33 \\
\hline \multirow[t]{3}{*}{ MAXAB } & \begin{tabular}{c|} 
Pears on \\
Correlation
\end{tabular} & & & -.535 & -.561 & & .928 & & & .523 & .515 \\
\hline & Sig. (2-tailed) & & & .001 & .001 & & .000 & & & .002 & .002 \\
\hline & $\mathrm{N}$ & & & 33 & 33 & & 33 & & & 33 & 33 \\
\hline \multirow[t]{3}{*}{ MEANAB } & \begin{tabular}{c|} 
Pears on \\
Correlation
\end{tabular} & & & -.482 & -495 & 928 & & & & .618 & .625 \\
\hline & Sig. (2-tailed) & & & .004 & .003 & .000 & & & & .000 & .000 \\
\hline & $\mathrm{N}$ & & & 33 & 33 & 33 & & & & 33 & 33 \\
\hline \multirow[t]{3}{*}{ MAXCIC } & \begin{tabular}{c|} 
Pears on \\
Correlation
\end{tabular} & -.417 & - 399 & & & & & & .960 & .766 & .739 \\
\hline & Sig. (2-tailed) & .034 & ..022 & & & & & & .000 & .000 & .000 \\
\hline & $\mathrm{N}$ & 26 & 33 & & & & & & 33 & 33 & 33 \\
\hline \multirow[t]{3}{*}{ MEANCIC } & \begin{tabular}{c|} 
Pears on \\
Correlation
\end{tabular} & -.420 & -.407 & & & & & .960 & & .775 & .761 \\
\hline & Sig. (2-tailed) & .033 & .019 & & & & & .000 & & .000 & .000 \\
\hline & $\mathrm{N}$ & 26 & 33 & & & & & 33 & & 33 & 33 \\
\hline \multirow[t]{3}{*}{ MAXPAG } & \begin{tabular}{c|} 
Pears on \\
Correlation
\end{tabular} & -.598 & & & -.387 & .523 & .618 & .766 & .775 & & .995 \\
\hline & Sig. (2-tailed) & .001 & & & .026 & .002 & .000 & .000 & .000 & & .000 \\
\hline & $\mathrm{N}$ & 26 & & & 33 & 33 & 33 & 33 & 33 & & 33 \\
\hline \multirow[t]{3}{*}{ MEANPAG } & \begin{tabular}{c|} 
Pears on \\
Correlation
\end{tabular} & -.581 & & & -.386 & .515 & .625 & .739 & .761 & .995 & \\
\hline & Sig. (2-tailed) & .002 & & & .027 & .002 & .000 & .000 & .000 & .000 & \\
\hline & $\mathrm{N}$ & 26 & & & 33 & 33 & 33 & 33 & 33 & 33 & \\
\hline
\end{tabular}

Pearson's correlation coefficient ( $r$ ) and Spearman's coefficient of rank correlation (2-tailed) calculated by aid of up-to-date SPSS software were used to statistically determine the strength of association within and between clinical and virus infection variables. For abbreviations and further details, see Methods

value of high initial antibodies was also found for pronounced improvement of the self-rating well-being score BfS by week 7. Likewise, initial antigen levels predicted clinical improvement (RDHAMD) both at MAX and MEAN levels (MAXPAG $r=-.387 ; p=0.026$, and MEANPAG $r=-.386 ; p=0.027)$. In contrast, initial CIC levels displayed no predictive power for the clinical course, but a significant correlation between their MAX and MEAN pre-treatment levels and pronounced CIC reduction by week 7 could be measured (MAXCIC $r=$ $.399 ; \quad p=0.022$, and MEANCIC $r=-.407 ; p=$ 0.019) (Table 7; DCIC18).

To further highlight treatment outcomes of amantadine and placebo vs. infection in Period I, the relationship of pre-treatment antibody (MAXAB) and antigen levels (MAXPAG, MEANPAG) to HAMD reduction on week 7 (rDHAMD7) as well as of MAXAB and improved self-rated well-being were illustrated (Fig. 7a-d). Correlations of total treatment outcome (rDHAMD7) with maximum pre-treatment loads of either antibody or antigen were additionally provided (Additional file 6: Figure S2 and S3).

\section{Sustainability}

Clinical improvement in the 12-months post-study follow-up was significantly correlated with dropped overall infection variables over time. A covariance analysis revealed a significant correlation between the mean HAMD-scores and the mean amount of BDV-1 infection scores, when cumulative scores $(\mathrm{CIC}+\mathrm{PAG}+\mathrm{AB})$ were considered $(\mathrm{t}=-3.51 ; p<0.001)$. 


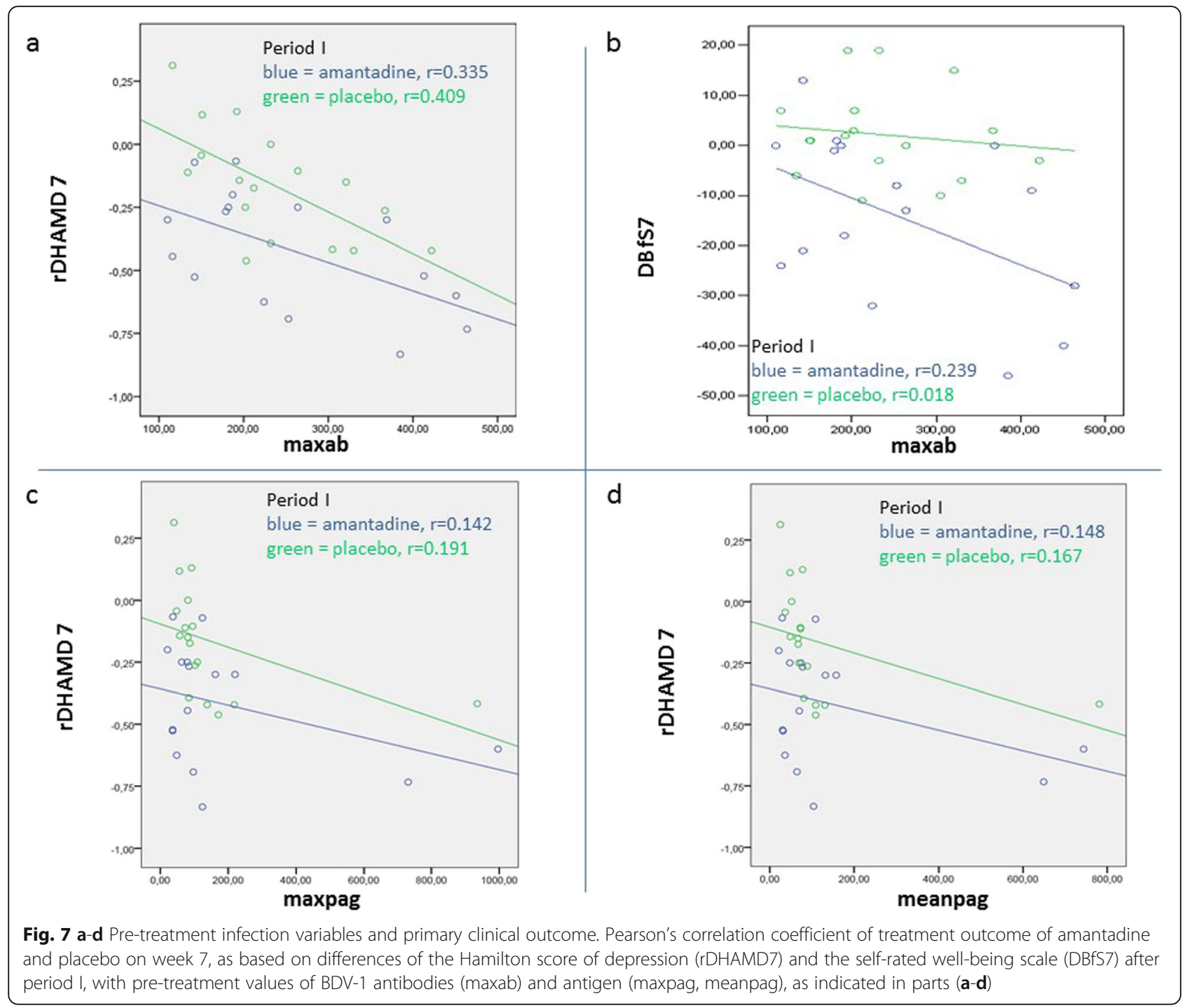

\section{In vitro efficacy studies}

\section{Prevention of infection}

The efficacy of amantadine and memantine to prevent BDV-1 infection was compared according to the 50\% infection-inhibitory dose (ID ${ }_{50}$ ). Based on ID ${ }_{50}$, an amantadine dose as low as 2.4 to $10 \mathrm{ng} / \mathrm{mL}$ prevented infection with human strain BDV $\mathrm{Hu}-\mathrm{H} 1$, while the closely related compound memantine failed up to a 100 , 000 times higher concentration of $200 \mu \mathrm{g} / \mathrm{mL}$ in the parallel experiment, as demonstrated in Fig. 8.

\section{Inhibition of replication}

The dose-dependent extraordinary antiviral efficacy of amantadine was further demonstrated in that the in vitro medium dose of amantadine $(0.4 \mu \mathrm{g} / \mathrm{mL})$ which abrogated the above tested human BDV-1 strain by 4 weeks, corresponded to the in vivo blood level resulting from the dose of $200 \mathrm{mg}$ orally per day applied in patients of the here described trial. Notably, the non-natural laboratory strain $\mathrm{V}$ was insensitive up to the highest in vitro dose of $1.2 \mu \mathrm{g} / \mathrm{mL}$ (Additional file 7: Figure S4), a finding consistent with the significant biological differences of these two strains $[22,23]$.

\section{Discussion}

"No health without mental health" stated the World Health Organization (WHO) according to the 2010 Global Burden of Disease Study [1]. The here reported RCT followed a novel rationale which aimed to open a new avenue to safe, cost-effective and sustainable treatment of depressive disorders applicable also in low resource settings. Two provocative hypotheses contested since 


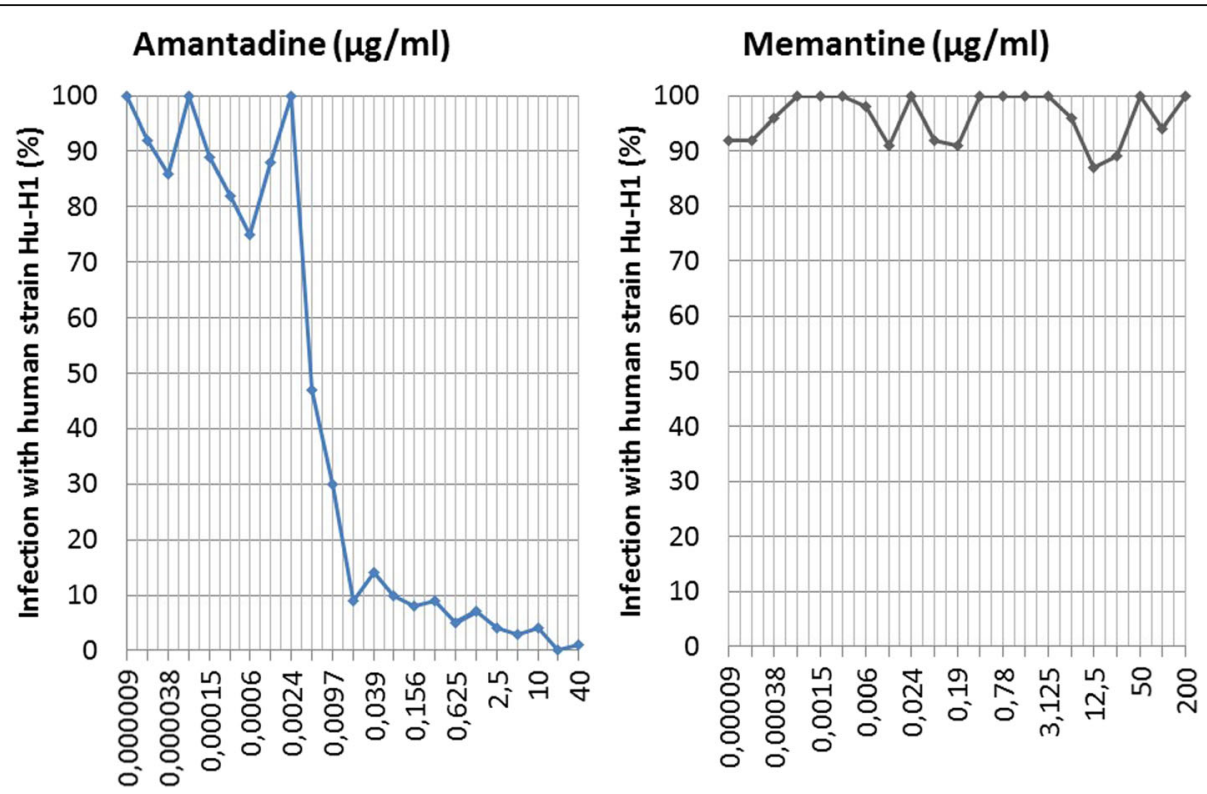

Fig. 8 In vitro prevention of infection comparing amantadine and memantine. Prevention-of-infection test by indicated doses of amantadine and memantine in vitro, using young rabbit spleen cells (YRS p108) and human BDV strain Hu-H1 (p55); $\mathrm{p}=$ passage

two decades were combined, namely whether depression could be linked to infection with a putatively moodmodulating virus (BDV-1) [14-17], and whether antiviral capacity of a well-known drug (amantadine) with yet ambiguous modes of action [5] could work as safe and well-tolerated antidepressant in infected patients. Testing an infectious contribution of BDV-1 to mental health, particularly depression, meant to be on a rocky path from the start, because human infection was doubted [25], despite evidence at different levels [2038]. Recently, human BDV-1 infection became an incontrovertible fact by reports on its ability to even cause fatalities $[18,19]$, emphasizing the broad capacity of BDV1 as a human pathogen.

\section{Clinical outcomes}

This first RCT conducted in a placebo-controlled double-blind cross-over design (twice 7 weeks) could validate both antidepressant and antiviral efficacy of amantadine in BDV-1 infected depressed MD or BD patients. The study not only confirmed our 20-years old pilot case report [6], but even outweighed response rates of two similarly sized open trials (68 and $63 \%$, respectively) [7, $8]$ by achieving a primary response of $81.3 \%$ on amantadine vs. $35.3 \%$ on placebo after 7 weeks $(p=0.003)$. Our phase II RCT could also confirm that an oral dose of twice $100 \mathrm{mg}$ daily of amantadine sulphate (PK-Merz $\left.{ }^{\circ}\right)$ [6-8] is well-tolerated in that neither serious adverse events (SAEs) nor significant SAE differences between amantadine and placebo periods were observed.
What the outcome data revealed were not only a strong statistical difference of DHAMD scores between amantadine and placebo treatment groups, but a pronounced clinical significance according to the large effect size (ES; Cohen's d) [49] of 1.05 (primary outcome week 7). ES values of $0.2,0.5$, and 0.8 were proposed to represent small, medium, and large effects, respectively $[3,49]$. Amantadine efficacy in our trial even tripled overall ES values of 0.32 and 0.31 , respectively, found for antidepressants including SSRIs in independent metaanalyses $[55,56]$. According to a more recent analysis comparing three widely prescribed SSRIs which revealed a better ES magnitude (0.5) after excluding suboptimal doses [57], our trial came up with at least double ES values. Antidepressants were compromised by selective reporting of positive results [56]. Of seventy-four RCTs on twelve antidepressants involving more than 12,000 patients, studies judged positive by the Food and Drug Administration (FDA) (51\%) were 12 times as likely to be published as were studies with non-positive results according to FDA $(p<0.001)$. Furthermore, the overall mean ES values were significantly different between published and unpublished studies reviewed by the FDA (0.37 and 0.15 , respectively) [56]. Beyond this criticism, each drug was shown by meta-analysis to be superior to placebo although less than indicated by the literature. Their clinical significance, however, of overall 0.3 is still on debate, based on whether a sharp cut off of 0.5 proposed as medium ES value were used [55] instead of a more continuous measure for drug efficacy [3]. Whatever effect sizes of antidepressants were deemed beneficial 
in RCTs that of amantadine appeared to outreach them all. Like for total HAMD-21, amantadine was significantly superior to placebo across all measured single items of HAMD, with a large mean ES of 0.834 (week 7) for depressed mood, feeling of guilt, suicidal behaviour, work and activities, psychic anxiety, sexual function, and dayvariations.

The risk of suicidal behaviour, especially in the context of SSRI treatment, has raised considerable attention and remained an unmet problem [4]. A large study using the UK General Practice Research Database of the years 1993-1999 revealed that the risk of suicidal behaviour was increased in the first 4 weeks of antidepressants, particularly during the first 1 to 9 days [52]. A similar time-frame was found by a Swedish register-based nationwide case-crossover study, reporting a peak in suicide risk during the second and third week after initiation of SSRI therapy [53]. It is therefore of particular interest that in contrast in our study, amantadine significantly reduced suicidal behaviour as early as by 2 weeks of treatment $(p=0.039, \mathrm{ES}=0.662)$, earlier than the total HAMD score, thereby getting beyond the above safety gap of SSRIs.

Another unmet need in the orthodox treatment of depression concerns cognitive dysfunction which impedes functional recovery in a significant proportion of MD patients [54]. Notably, in this study, we could document a significant and lasting improvement of the HAMD cluster referring to retardation (DRETARD) by amantadine as early as by 2 weeks of treatment.

Particularly the lag period of antidepressants of several weeks, increasing suicide risks before mood improvements appear, has shifted current research towards rapid-acting substances targeting the glutamatergic system. Ketamine, a non-competitive high-affinity NMDA antagonist of glutamate and licensed anaesthetic agent, has emerged as a promising candidate, since a single sub-anaesthetic intravenous dose $(0.5 \mathrm{mg} / \mathrm{kg})$ has elicited rapid improvement in depressed patients after $24 \mathrm{~h}$, lasting 1-2 weeks. However, a broader application needs to address ketamine's critical obstacles that is whether the rapid anti-depressive effects can be maintained over longer periods and self-administered application modes can be developed [58]. In view of our findings, amantadine appeared the by far more promising option compared to ketamine. Provided the early drop of suicidal behaviour holds true in larger RCTs, it could help saving patients' lives. At least, earlier suggested adverse safety effects considering short-term psychotropic effects [5] could be ruled out. Likewise, the unexpectedly long 12-months post-study sustainability of beneficial amantadine therapy argued against mainly short-term psychotropic modes of action, the more since reduced severity and duration of further depressive episodes correlated with dropped cumulative infection measures over time $(p<$ $0.001)$.

Notably, sustainability of amantadine therapy could also be suggested from an unexpected result of the ethically requested cross-over design of the RCT. The majority of patients who responded to amantadine treatment in Period I (Group A), maintained their response under placebo in Period II, after 14 weeks (69.2\%). With respect to whole Group A, even $80 \%$ were responders after cross-over. This was doubling the primary response of patients to placebo treatment in Period I (35.3\%) (Group P). Therefore, sustained amantadine efficacy may be a much more likely explanation than possible carry-over effects given the half-life of amantadine (10-31 h).

The overall clinical assessment revealed $74.2 \%$ of all study patients who benefitted from treatment after cross-over, by week 14, which exceeded response rates of 12 -weeks open trials $[7,8]$. Even $82.1 \%$ of patients benefitted from optional post-study amantadine treatment after 12 further months.

\section{BDV infection and depression}

The "mood virus hypothesis" of depression [15-17] was previously supported but as yet not confirmed by a couple of findings. These were BDV-1's ability of lifelong persistence [14] in brain and blood cells of humans and many animal companions, high affinity to the hippocampus [14], behavioural and cognitive changes (animals) [14], human virus isolates [20,21, 24], and higher prevalence data (antibodies, RNA) in psychiatric patients than controls [26-38, 40,48]. An independent intriguing line of evidence suggested a long-term co-evolution of BDV-1 with human hosts by endogenous Borna-like $\mathrm{N}$ protein elements (EBLNs), integrated into the germ-line of humans and their predecessors since more than 40 million years $[59,60]$.

The here reported findings provided strong further support to the "mood virus hypothesis" in that dropped BDV-1 infection activity paralleled dropped depression using a drug which was shown to have anti-BDV efficacy (in vivo and in vitro) in a pilot case study [6]. However, due to amantadine's known antidepressant effects [5], the main mode of action needs to be further clarified. Notably, amantadine had also been shown to have significant anti-manic effects in BDV-infected bipolar I or bipolar II inpatients in a pilot trial. The overall symptom reduction after 18 days was $79.2 \%(p<0.001)$, and the treatment was well-tolerated [61]. Anti-manic efficacy of amantadine was unexpected given its reported pharmacological properties [5]. This argued again in favour of the drug's anti-BDV capacity eliciting anti-manic clinical effects, even though reduced blood BDV activities could 
not be measured due to the too short observation period [61].

Activity measures were made available through the previous discovery of virus protein (antigen)-driven infection dynamics in any mammalian host. BDV-1 replication periods lead to excess production of antigen which induces host antibodies, both mainly forming antigen/antibody (PAG/AB) complexes circulating in blood plasma (CIC), while at the same time, levels of unbound PAG as well as AB are dropping [41].

\section{Infection outcomes}

A modular easy-to-use EIA allowed quantitative longitudinal infection profiling of CIC, PAG, and AB throughout the trial, in parallel to clinical outcome scores. Up to almost 600 tests per assay and a mean number of 17 samples per patient were performed. In-depth analysis of the wealth of data addressed first whether and how infection variables were correlating with each other, and secondly whether and how infection and clinical variables were related. We could demonstrate a strong quantitative relationship of pre-treatment $\mathrm{CIC}$ and $\mathrm{AB}$ with PAG. Similarly validated assay results using the same EIA system were recently reported in a Lithuanian study [62]. In our trial, pre-treatment PAG- and CIClevels correlated with $\mathrm{AB}$-level reduction in the first treatment period. Notably, the initial infection load (PAG and $\mathrm{AB}$ ) had a strong significant predictive value for short-term clinical improvement (primary response; RDHAMD) after 7 weeks. In contrast to these direct virus and host-derived variables, pre-treatment levels of their combined product (CIC) displayed no correlation to the short-term clinical improvement, but did so on the long run. Decreased CIC together with decreased PAG and AB correlated with 12-months post study clinical improvements. This remarkable finding suggested a sustainable antiviral effect against BDV-1 activity, and the likely relationship with a sustainable anti-depressive benefit.

$\mathrm{CIC}$ values change through antigen increase/decrease as well as antibody increase/decrease in lag time. While CIC profiles can well serve as therapy control of individual patients [15], they need to be complemented by PAG and/or $A B$ profiles when mean values of patient groups are evaluated. Our study thus showed that patients' blood monitoring, due to the interdependence and dynamic of BDV-1 infection variables CIC, PAG and AB, should include their complete profile, prior to, during, and after treatment. In practical terms, an important outcome of our study revealed that high PAG and $A B$ levels in depressed patients could predict who will be likely to benefit from antiviral treatment. In so far, the study provided clear correlative evidence for a significant contribution of the infection to depression. The antiviral in vivo efficacy of amantadine had been previously demonstrated independently of clinical effects in remitted BDV-1 infected patients with affective disorders, applying a double-blind placebo-controlled design over 14 weeks. Activity-related variables (PAG and $\mathrm{CIC}$ ) were significantly reduced $(p=0.028$ and $p=0.003$, respectively), as well as antibodies (AB; $p=0.007$ ) [63].

$\mathrm{CIC}$ have been shown to be first-rate prevalence variables, superior to RNA- and antibody- only approaches. Cross-sectional studies within and between countries benefited from comparability and user friendly applicability of the BDV-CIC-EIA [64-68]. However, a general acceptance of the EIA systems is still pending even though epitope mapping and recombinant protein validated their specificity and sensitivity [47]. An attempt to question specificity reported failure to detect antigens [69], but used an inappropriate procedural approach, and did not determine through parallel experiments using recombinant proteins whether his approach met the same detection level (1.5-3.0 ng antigen $/ \mathrm{mL})$ achieved in our antigen-EIA [47]. The here reported study may contribute to overcome current reservations.

In conclusion, infection variables prior and post amantadine therapy were shown to be interlocked with clinical outcomes, supporting the rationale of cross-linking BDV-1 infection with depression. However, the extent to which the antidepressant efficacy of amantadine is based on its antiviral capacity against BDV-1 infection in vivo, needs to be further evaluated. This could be addressed in future studies using other antivirals with known antiBDV-1 but lacking antidepressant effects, such as the nucleoside analogues ribavirin and favipiravir (T-705). Early ribavirin in vitro studies had used human OL cells and rat glia cells (C6) persistently infected with laboratory strains $\mathrm{V}$ and $\mathrm{He} / 80$, respectively. They found a > 90\% titre decline in both cell/virus systems within 3 days, applying $20 \mu \mathrm{M}$ ribavirin up to 13 days, but a rapid virus recovery within 2 days after drug removal [70]. Recently, favipiravir, a new potent antiviral drug against a wide spectrum of viruses, was shown to be more effective than ribavirin against BDV-1. Favipiravir rapidly reduced BDV-1 infection at $200-400 \mu \mathrm{M}$ to almost undetectable levels by 21 days using a recombinant virus system in Vero cells, and natural virus in OL cells persistently infected with $\mathrm{He} / 80$ at $400 \mu \mathrm{M}$ by 28 days [71]. Equivalent in vivo plasma levels of favipiravir $(446 \mu \mathrm{M}$; $70 \mu \mathrm{g} / \mathrm{mL}$ ) have been successfully applied in a lethal non-human primate model against Ebola virus disease, reducing the median viral load at day 7 by $2-3 \operatorname{logs}$ [72]. In contrast to amantadine, however, the clinical application of both these drugs is associated with the risk of significant adverse effects. With respect to ribavirin, namely headache, fever, muscle pain and irritable mood 
were known, the latter most unfavourable in the treatment of depressed patients. Favipiravir has a risk of dose-related haemolytic anaemia, teratogenicity, and embryo-toxicity.

\section{In vitro findings}

To further address the rationale of a mainly antiviral mode of action for amantadine, we extended in vitro efficacy studies of amantadine (1-aminoadamantane) to the closely related derivative memantine (1-amino-3,5dimethyladamantane). Alike amantadine, memantine came into focus as low affinity non-competitive NMDA receptor antagonist with neuroprotective activity, but failed to show antidepressant effects in double-blind placebo- controlled RCTs [73, 74]. Here, we could show in vitro that amantadine was able to prevent infection $\left(\mathrm{ID}_{50}\right)$ of rabbit cells with human BDV strain $\mathrm{Hu}-\mathrm{H} 1$ [20] at concentrations as low as 2.4 to $10 \mathrm{ng} / \mathrm{mL}(0.005$ to $0.025 \mu \mathrm{M}$ ), while memantine failed up to a 100,000 fold higher concentration $(200 \mu \mathrm{g} / \mathrm{mL} ; 500 \mu \mathrm{M})$. Interestingly, the in vitro medium dose of amantadine which abrogated replication of the same human strain by 4 weeks $(0.4 \mu \mathrm{g} / \mathrm{mL} ; 1 \mu \mathrm{M})$, corresponded exactly to the in vivo blood level achieved through the dose of $200 \mathrm{mg}$ amantadine orally daily applied in patients of our trial. In contrast, laboratory-adapted str. V [14] was insensitive to amantadine treatment up to the highest dose of $1.2 \mu \mathrm{g} /$ $\mathrm{mL}(3 \mu \mathrm{M})$, consistent with largely different biological properties of natural and non-natural strains [22, 23]. It should be noted that the remarkable insensitivity of BDV-1 laboratory strains observed earlier by different researchers [75-77], had quite a while led to a general questioning of amantadine's anti-BDV efficacy. Here, we could finally dispel anybody's doubts by demonstrating the fundamental differences between a natural human isolate and a highly adapted laboratory strain in parallel in vitro experiments. Virus-host differences had also been suggested to impact the antiviral potency of ribavirin, even though only two laboratory strains with comparable adaptations had been compared [70].

Amantadine and memantine are closely related adamantanes with not fully clarified diverse neuropharmacological properties [5]. Memantine neither acted as antiviral in vitro, nor elicited antidepressant efficacy above placebo [73, 74], whereas amantadine did so in this and previous open trials [6-8]. It therefore appears plausible that amantadine's contrasting bipartite capacity may be part of a common chief mode of action, unrelated to that of memantine. Notably, experimental animal evidence suggested a key impact of BDV-1 infection on the glutamate system, targeting non-NMDA receptors of the kainate-type (KARs), specifically KA1 [78]. KARs were thought to be involved in neuronal plasticity, indispensable for memory functioning and learning [79,
80]. This would be consistent with cognitive deficiencies found earlier in BDV-1 infected rats [81]. Against this background, it appeared not too speculative that depression, amantadine, and BDV-1 infection might be linked through crosstalk at different glutamate receptor sites.

Our overall findings provided convincing evidence that oral amantadine treatment at a well-tolerated dose of $200 \mathrm{mg} /$ day for at least 6 weeks was highly beneficial in $\mathrm{MD}$ and BD patients with BDV-1 infection, by far outweighing effect sizes of antidepressants. Amantadine impacted profoundly to safety by rapidly reducing the suicide risk earlier than SSRIs [4, 52, 53], after 2 weeks. The small study size was, however, a clear disadvantage. The cross-over design was a legitimate ethical request but implied a further disadvantage in that possible carryover effects from the first treatment period were suggested to limit sound in-depth statistical analysis of Period II. However, unexpectedly, cross-over from amantadine to placebo resulted in maintained response in a majority of patients, arguing for favourable sustainability of amantadine therapy.

Provided large-scale studies could validate generalizability for this report, it could pave the way to a practice-changing, low cost and, in contrast to ketamine [58], easy applicable and safe mental health care perspective. Our evidencebased antiviral approach may thus also meet the needs in countries with limited resources [1].

\section{Conclusions}

We applied the design of a double-blind placebocontrolled phase II RCT which cross-linked depression and BDV-1 infection to evaluate the antidepressant and antiviral effect of amantadine. Clinical and infection outcomes could provide the following evidence:

1. Amantadine had significant antidepressant efficacy (multi-item scores) over placebo in depressed patients with BDV-1 infection.

2. The clinical effect size (Cohen's d-value) of amantadine tripled the overall effect size which had been calculated for orthodox antidepressants including SSRIs by independent meta-analysis.

3. Two major unsolved problems associated with orthodox treatment of depression, namely the risk of suicidal behaviour and cognitive dysfunction, were significantly decreased by amantadine as early as after the first 2 weeks.

4. Amantadine was safe at a daily dose of $200 \mathrm{mg}$ and adverse events are non-significant compared to placebo.

5. Amantadine had antiviral efficacy both in infected patients and in vitro.

6. Amantadine's antidepressant efficacy in vivo correlated with antiviral capacity against BDV-1 
infection in that at least a combined antiviral/antidepressant effect was suggestive.

These findings supported the paradigm of a contributory role of BDV-1 infection in depression. Screening for BDV-1 infection using easy accessible serum or plasma samples could open the window to a new very cost effective treatment option suitable for depressed infected patients. Our study clearly showed the benefit of amantadine for these patients exceeding that of orthodox antidepressants with respect to effect size and safety. Our findings thus anticipate a novel possibly practicechanging mental health care perspective for depressed BDV-1 infected patients which may even be applicable at a global scale. At least, our novel approach could inspire the conduct of large-scale clinical studies which are needed to further examine the generalizability of our findings.

\section{Supplementary information}

Supplementary information accompanies this paper at https://doi.org/10. 1186/s40360-020-0391-x

Additional file 1. Trial registration.

Additional file 2. Study history and disclaimer.

Additional file 3: Table S1. Overall clinical response.

Additional file 4: Figure S1. Cumulative effect size development.

Additional file 5: Table S2. Reported single adverse effects.

Additional file 6: Total treatment outcome (RDHAMD week 7) correlated with pre-treatment antibody load (Figure S2) and antigen load (Figure S3)

Additional file 7: Figure S4. In vitro inhibition of replication comparing human and laboratory strains.

\begin{abstract}
Abbreviations
AB: Antibodies; BD: Bipolar disorder; BDV: Borna disease virus; BfS: Mental health self-rating score (von Zerssen); CIC: BDV circulation immune complexes; DALYs: Disability-adjusted life years; EIA: Enzyme immune assay; ES: Effect size (Cohen's d); FDA: Food and Drug Administration; HAMD: Hamilton rating scale for depression; IFT: Indirect immune fluorescence test; KARs: Kainate receptors; mABs: Monoclonal antibodies; MD: Major depression; MHH: Hannover Medical School; NMDA: N-methyl-Daspartate; OL: Human oligodendroglia; PAG: BDV antigens (N, P proteins, N/P heterodimer); PBMCs: Peripheral blood mononuclear cells; PBS: Phosphatebuffered saline; RCT: Randomized clinical trial; RNA: Ribonucleic acid; SCL90R: Self-rating symptoms checklist; SSRIs: Serotonin reuptake inhibitors; WHO: World Health Organization; YRS: Young rabbit spleen
\end{abstract}

\section{Acknowledgements}

We are deeply grateful to Roman Stoyloff $(\mathrm{PhD})$ for conducting the in vitro experiments at the Institute of Virology (headed by HL), Free University of Berlin, Berlin, Germany (2000). We greatly appreciated medical care and support in psychiatric examination of study patients by Thomas J. Huber (MD), Thomas Gödecke-Koch (MD), Beatrice Durchleuchter, Martina Lunar, Katrin Kipp, Annett Kleinschmidt, and Nadine Gerhard at the (former) Department of Clinical Psychiatry and Psychotherapy, Hannover Medical School, Hanover, Germany (1997-1999). We are particularly grateful to Bonita Brodhun (PhD) for establishing and administering a huge data base for patients' samples and results from virological assays (1997-1999); Aemero Muluneh (DVM) for conducting IFT antibody assays (1997-1998); and Patrizia Reckwald (chief medical technical assistant) who conducted the entire infection testing by the different EIAs throughout the study, for excellent technical assistance, supported by indispensable work of Gülsüm Baykal and Christine Berndt who were responsible for coding, processing and storage of patients' plasma and PBMCs at $-20^{\circ} \mathrm{C}$ and $-80^{\circ} \mathrm{C}$ freezers, respectively (19972002); all were staff members of the Project Bornavirus Infections (headed by LB) at the Robert Koch Institute (RKI), Berlin, Germany, until end of project in 2005 (Additional file 2: Study history and disclaimer).

\section{Authors' Contributions}

DED and LB contributed equally to this work. DED, LB, HME and HL contributed to the overall conception and design of the study. DED and CWS carried out the clinical part and LB the virological part of the study. HME and $\mathrm{HL}$ supervised the conduction of respective study parts. DED and LB undertook the extraction of clinical and virological data, respectively, supported by $\mathrm{HH}$. $\mathrm{HH}$ did the formal data analysis and the complete statistical analysis. All authors contributed to methodology and interpretation of results. $L B$ and DED wrote drafts of previous versions of the manuscript. LB wrote, reviewed and edited the final manuscript. All authors read and approved the final manuscript, except HME who passed away in September 2018 and approved a pre-final version with identical data sets and interpretation.

\section{Funding}

There was no study-specific financial support acquired. The study was conducted in publicly funded institutions (see Additional file 2: Study history and disclaimer) upon regular financial resources.

\section{Availability of data and materials}

The datasets generated and/or analysed during the current study are not publicly available due to protection of individual privacy of participants, but are available from the corresponding authors on reasonable request.

\section{Ethics approval and consent to participate}

The study was approved by the local Ethics Committee (Reference No. 15081997) of the Hannover Medical School (MHH), Hanover, Germany. All participants signed written informed consent.

\section{Consent for publication}

Not applicable.

\section{Competing interests}

The authors of this manuscript have the following competing interests: DED and $\mathrm{HL}$ held non-licensed common patents on a 2nd indication of amantadine (Germany, USA, China, and Japan) which are expired. HL held nonlicensed patents on BDV diagnostic procedures (Germany and USA) which are also expired. $\mathrm{HL}$ received personal consulting fees from medical laboratories in Germany, Diamedis (https://www.diamedis.eu) and DEDIMED (https://dedimed.com). LB and HL report a common patent application on differential BDV-1 diagnosis (first publication on 11th April, 2019) by the German Patent and Trade Mark Office), and personal fees from R-Biopharm (https://r-biopharm.com/de). CWS is a full-time employee of Idorsia Pharmaceuticals (Allschwil, Switzerland). HH and HME declared they have no competing interests.

\section{Author details}

'Department of Psychiatry, Burghof-Clinic, Ritterstr. 19, 31737 Rinteln, Germany. ${ }^{2}$ Center for Systems Neuroscience, Bünteweg 2, 30559 Hanover, Germany. ${ }^{3}$ Department of Mental Health, Hannover Medical School, Carl-Neuberg-Str. 1, 30625 Hanover, Germany. ${ }^{4}$ Joint Senior Scientists, Freelance Bornavirus Workgroup, Beerenstr. 41, 14163 Berlin, Germany. ${ }^{5}$ Department of Biometrics, Hannover Medical School, Carl-Neuberg-Str. 1, 30625 Hanover, Germany.

Received: 29 March 2019 Accepted: 5 February 2020

Published online: 17 February 2020

\section{References}

1. Patel V, Saxena S. Transforming lives, enhancing communities--innovations in global mental health. N Engl J Med. 2014;370(6):498-501. https://doi.org/ 10.1056/NEJMp1315214

2. Ferrari AJ, Norman RE, Freedman G, Baxter AJ, Pirkis JE, Harris MG, et al. The burden attributable to mental and substance use disorders as risk factors for 
suicide: findings from the Global Burden of Disease Study 2010. PLoS One. 2014;9(4):e91936. https://doi.org/10.1371/journal.pone.0091936.

3. Turner EH, Rosenthal R. Efficacy of antidepressants. BMJ. 2008;336(7643): 516-7. https://doi.org/10.1136/bmj.39510.531597.80.

4. Penn E, Tracy DK. The drugs don't work? Antidepressants and the current and future pharmacological management of depression. Ther Adv Psychopharmacol. 2012;2(5):179-88. https://doi.org/10.1177/ 2045125312445469.

5. Huber TJ, Dietrich DE, Emrich HM. Possible use of amantadine in depression. Pharmacopsychiatry. 1999;32(2):47-55 Review.

6. Bode L, Dietrich DE, Stoyloff R, Emrich HM, Ludwig H. Amantadine and human Borna disease virus in vitro and in vivo in an infected patient with bipolar depression. Lancet. 1997;349(9046):178-9.

7. Dietrich DE, Bode L, Spannhuth CW, Lau T, Huber TJ, Brodhun B, et al. Amantadine in depressive patients with Borna disease virus (BDV) infection: an open trial. Bipolar Disord. 2000;2(1):65-70.

8. Ferszt R, Kühl KP, Bode L, Severus EW, Winzer B, Berghöfer A, et al, Amantadine revisited: an open trial of amantadinesulfate treatment in chronically depressed patients with Borna disease virus infection. Pharmacopsychiatry. 1999;32(4):142-7.

9. Lipkin WI, Briese T. Bornaviridae. In: Knipe D, Howley P, Griffin D, Lamb R, Martin M, Roizman B, Straus S, editors. Fields Virology, vol. II. 5th ed. Philadelphia PA: Lippincott Williams and Wilkins; 2007. p. 1829-51.

10. Kuhn JH, Dürrwald R, Bào Y, Briese T, Carbone K, Clawson AN, et al. Taxonomic reorganization of the family Bornaviridae. Arch Virol. 2015;160(2): 621-32. https://doi.org/10.1007/s00705-014-2276-z.

11. Briese T, Schneemann A, Lewis AJ, Park YS, Kim S, Ludwig H, et al. Genomic organization of Borna disease virus. Proc Natl Acad Sci U S A. 1994;91(10): 4362-6.

12. Cubitt $\mathrm{B}$, Oldstone $\mathrm{C}$, de la Torre JC. Sequence and genome organization of Borna disease virus. J Virol. 1994;68(3):1382-96.

13. Hoffmann B, Tappe D, Höper D, Herden C, Boldt A, Mawrin C, et al. A Variegated Squirrel Bornavirus Associated with Fatal Human Encephalitis. N Engl J Med. 2015;373(2):154-62. https://doi.org/10.1056/NEJMoa1415627.

14. Ludwig H, Bode L, Gosztonyi G. Borna disease: a persistent virus infection of the central nervous system. Prog Med Virol. 1988;35:107-51 Review.

15. Bode L, Ludwig H. Borna disease virus infection, a human mental-health risk. Clin Microbiol Rev. 2003:16(3):534-45 Review.

16. Ludwig H, Bode L. From latent Herpes viruses to persistent Bornavirus. In: Blaho JA, Baines JD, editors. From the hallowed halls of Herpesvirology. A tribute to Bernhard Roizman. New York: World Scientific Publishing Co. Pte. Ltd., Hackensack; 2012. p. 169-86.

17. Dietrich DE, Schedlowski M, Bode L, Ludwig H, Emrich HM. A viro-psychoimmunological disease-model of a subtype affective disorder. Pharmacopsychiatry. 1998;31(3):77-82 Review.

18. Schlottau K, Forth L, Angstwurm K, Höper D, Zecher D, Liesche F, et al. Fatal Encephalitic Borna Disease Virus 1 in Solid-Organ Transplant Recipients. N Engl J Med. 2018;379(14):1377-9. https://doi.org/10.1056/NEJMc1803115.

19. Korn K, Coras R, Bobinger T, Herzog SM, Lücking H, Stöhr R, et al. Fatal Encephalitis Associated with Borna Disease Virus 1. N Engl J Med. 2018; 379(14):1375-7. https://doi.org/10.1056/NEJMc1800724.

20. Bode L, Dürrwald R, Rantam FA, Ferszt R, Ludwig H. First isolates of infectious human Borna disease virus from patients with mood disorders. Mol Psychiatry. 1996;1 (3):200-12.

21. Nakamura $Y$, Takahashi H, Shoya $Y$, Nakaya T, Watanabe M, Tomonaga $K$, et al. Isolation of Borna disease virus from human brain tissue. J Virol. 2000; 74(10):4601-11.

22. Li D, Lei Y, Deng J, Zhou C, Zhang Y, Li W, et al. Human but Not Laboratory Borna Disease Virus Inhibits Proliferation and Induces Apoptosis in Human Oligodendrocytes In Vitro. PLoS One. 2013;8(6):e66623. https://doi.org/10. 1371/journal.pone.0066623.

23. Liu S, Bode L, Zhang L, He P, Huang R, Sun L, et al. GC-MS-Based Metabonomic Profiling Displayed Differing Effects of Borna Disease Virus Natural Strain Hu-H1 and Laboratory Strain V Infection in Rat Cortical Neurons. Int J Mol Sci. 2015;16(8):19347-68. https://doi.org/10.3390/ ijms160819347.

24. de la Torre JC, Bode L, Dürrwald R, Cubitt B, Ludwig H. Sequence characterization of human Borna disease virus. Virus Res. 1996;44(1):33-44.

25. Dürrwald R, Kolodziejek J, Herzog S, Nowotny N. Meta-analysis of putative human bornavirus sequences fails to provide evidence implicating Borna disease virus in mental illness. Rev Med Virol. 2007;17(3):181-203 Review.
26. Ikuta K, Ibrahim MS, Kobayashi T, Tomonaga K. Borna disease virus and infection in humans. Front Biosci. 2002;7:d470-95 Review.

27. Rott R, Herzog S, Fleischer B, Winokur A, Amsterdam J, Dyson W, et al. Detection of serum antibodies to Borna disease virus in patients with psychiatric disorders. Science. 1985;228(4700):755-6.

28. Bode L, Zimmermann W, Ferszt R, Steinbach F, Ludwig H. Borna disease virus genome transcribed and expressed in psychiatric patients. Nat Med. 1995;1(3):232-6.

29. Sauder C, Müller A, Cubitt B, Mayer J, Steinmetz J, Trabert W, et al. Detection of Borna disease virus (BDV) antibodies and BDV RNA in psychiatric patients: evidence for high sequence conservation of human blood-derived BDV RNA. J Virol. 1996;70(11):7713-24.

30. De La Torre JC, Gonzalez-Dunia D, Cubitt B, Mallory M, Mueller-Lantzsch N, Grässer FA, et al. Detection of borna disease virus antigen and RNA in human autopsy brain samples from neuropsychiatric patients. Virology. 1996;223(2):272-82.

31. Salvatore M, Morzunov S, Schwemmle M, Lipkin WI. Borna disease virus in brains of North American and European people with schizophrenia and bipolar disorder. Bornavirus Study Group. Lancet. 1997;349(9068):1813-4.

32. Iwahashi K, Watanabe M, Nakamura K, Suwaki H, Nakaya T, Nakamura Y, et al. Clinical investigation of the relationship between Borna disease virus (BDV) infection and schizophrenia in 67 patients in Japan. Acta Psychiatr Scand. 1997:96(6):412-5.

33. Chen CH, Chiu YL, Wei FC, Koong FJ, Liu HC, Shaw CK, et al. High seroprevalence of Borna virus infection in schizophrenic patients, family members and mental health workers in Taiwan. Mol Psychiatry. 1999;4(1): 33-8.

34. Rybakowski F, Sawada T, Yamaguchi K, Rajewski A, Rybakowski J. Borna Disease Virus--reactive antibodies in Polish psychiatric patients. Med Sci Monit. 2002:8(9):CR642-6.

35. Terayama H, Nishino Y, Kishi M, Ikuta K, Itoh M, Iwahashi K. Detection of anti-Borna Disease Virus (BDV) antibodies from patients with schizophrenia and mood disorders in Japan. Psychiatry Res. 2003;120(2):201-6.

36. Miranda HC, Nunes SO, Calvo ES, Suzart S, Itano EN, Watanabe MA. Detection of Borna disease virus p24 RNA in peripheral blood cells from Brazilian mood and psychotic disorder patients. J Affect Disord. 2006;90(1): 43-7.

37. Li Q, Wang Z, Zhu D, Xu M, Chen X, Peng D, et al. Detection and analysis of Borna disease virus in Chinese patients with neurological disorders. Eur J Neurol. 2009;16(3):399-403. https://doi.org/10.1111/j.1468-1331.2008.02516.x.

38. Zhang L, Xu MM, Zeng L, Liu S, Liu X, Wang X, et al. Evidence for Borna disease virus infection in neuropsychiatric patients in three western China provinces. Eur J Clin Microbiol Infect Dis. 2014;33(4):621-7. https://doi.org/ 10.1007/s10096-013-1996-4.

39. Hornig M, Briese T, Licinio J, Khabbaz RF, Altshuler LL, Potkin SG, et al. Absence of evidence for bornavirus infection in schizophrenia, bipolar disorder and major depressive disorder. Mol Psychiatry. 2012;17(5):486-93. https://doi.org/10.1038/mp.2011.179.

40. Wang X, Zhang L, Lei Y, Liu X, Zhou X, Liu Y, et al. Meta-analysis of infectious agents and depression. Sci Rep. 2014;4:4530. https://doi.org/10.1038/srep04530.

41. Bode L, Reckwald P, Severus WE, Stoyloff R, Ferszt R, Dietrich DE, et al. Borna disease virus-specific circulating immune complexes, antigenemia, and free antibodies--the key marker triplet determining infection and prevailing in severe mood disorders. Mol Psychiatry. 2001;6(4):481-91.

42. Hamilton M. Development of a rating scale for primary depressive illness. Br J Soc Clin Psychol. 1967;6(4):278-96.

43. American Psychiatric Association. Diagnostic and Statistical Manual of Mental Disorders (DSM-IV). 4th ed. Washington DC: American Psychiatric Association (APA); 1994.

44. von Zerssen D, Koeller DM, Rey ER. A scale for the objective evaluation of the state of subjective well-being as a method for longitudinal studies. Arzneimittelforschung. 1970;20(7):915-8 German.

45. Derogatis LR, Savitz KL. The SCL-90-R, Brief Symptom Inventory, and Matching Clinical Rating Scales. In: Maruish ME, editor. The use of psychological testing for treatment planning and outcomes assessment. Lawrence Erlbaum Associates Publishers; 1999. p. 679-724.

46. Ludwig H, Furuya K, Bode L, Klein N, Dürrwald R, Lee DS. Biology and neurobiology of Borna disease viruses (BDV), defined by antibodies, neutralizability and their pathogenic potential. Arch Virol Suppl. 1993;7:111-33.

47. Bode L. Human bornavirus infection-- towards a valid diagnostic system APMIS. 2008;116(Suppl 124):21-39 Review. 
48. Bode L, Riegel S, Lange W, Ludwig H. Human infections with Borna disease virus: seroprevalence in patients with chronic diseases and healthy individuals. J Med Virol. 1992;36(4):309-15.

49. Cohen J. Statistical power analysis for the behavioral sciences. 2nd ed. New York: Lawrence Erlbaum Associates; 1988.

50. Hedges LV, Olkin I. Statistical methods for meta-analysis. New York: Academic Press; 1985.

51. Ellis PD. Effect size calculators, 2009. Available from and accessed on August 24, 2016, at https://www.polyu.edu.hk/mm/effectsizefaqs/calculator/ calculator.html.

52. Jick H, Kaye JA, Jick SS. Antidepressants and the risk of suicidal behaviors. JAMA. 2004;292(3):338-43.

53. Björkenstam C, Möller J, Ringbäck G, Salmi P, Hallqvist J, Ljung R. An association between initiation of selective serotonin reuptake inhibitors and suicide - a nationwide register-based case-crossover study. PLoS One. 2013; 8(9):e73973. https://doi.org/10.1371/journal.pone.0073973.

54. Bortolato B, Miskowiak KW, Köhler CA, Maes M, Fernandes BS, Berk M, et al. Cognitive remission: a novel objective for the treatment of major depression? BMC Med. 2016;14:9. https://doi.org/10.1186/s12916-016-0560-3 Review.

55. Kirsch I, Deacon BJ, Huedo-Medina TB, Scoboria A, Moore TJ, Johnson BT. Initial severity and antidepressant benefits: a meta-analysis of data submitted to the Food and Drug Administration. PLoS Med. 2008;5(2):e45. https://doi.org/10.1371/journal.pmed.0050045.

56. Turner EH, Matthews AM, Linardatos E, Tell RA, Rosenthal R. Selective publication of antidepressant trials and its influence on apparent efficacy. $\mathrm{N}$ Engl J Med. 2008;358(3):252-60. https://doi.org/10.1056/NEJMsa065779.

57. Hieronymus F, Nilsson S, Eriksson E. A mega-analysis of fixed-dose trials reveals dose-dependency and a rapid onset of action for the antidepressant effect of three selective serotonin reuptake inhibitors. Transl Psychiatry. 2016;6(6):e834. https://doi.org/10.1038/tp.2016.104.

58. Naughton M, Clarke G, O'Leary OF, Cryan JF, Dinan TG. A review of ketamine in affective disorders: current evidence of clinical efficacy, limitations of use and pre-clinical evidence on proposed mechanisms of action. J Affect Disord. 2014;156:24-35. https://doi.org/10.1016/j.jad.2013.11. 014 Review.

59. Horie M, Honda T, Suzuki Y, Kobayashi Y, Daito T, Oshida T, et al. Endogenous non-retroviral RNA virus elements in mammalian genomes. Nature. 2010;463(7277):84-7. https://doi.org/10.1038/nature08695.

60. Belyi VA, Levine AJ, Skalka AM. Unexpected inheritance: multiple integrations of ancient bornavirus and ebolavirus/marburgvirus sequences in vertebrate genomes. PLoS Pathog. 2010;6(7):e1001030. https://doi.org/10. 1371/journal.ppat.1001030.

61. Ohlmeier MD, Zhang Y, Bode L, Sieg S, Feutl S, Ludwig H, et al. Amantadine reduces mania in borna disease virus-infected non-psychotic bipolar patients. Pharmacopsychiatry. 2008;41(5):202-3. https://doi.org/10.1055/s2008-1078748

62. Zaliunaite V, Steibliene V, Bode L, Podlipskyte A, Bunevicius R, Ludwig H. Primary psychosis and Borna disease virus infection in Lithuania: a case control study. BMC Psychiatry. 2016;16(1):369.

63. Dietrich DE, Bode L. Human Borna disease virus-infection and its therapy in affective disorders. APMIS Suppl. 2008;116(Suppl 124):61-5 Review.

64. Patti AM, Vulcano A, Candelori E, Ludwig H, Bode L. Borna disease virus infection in the population of Latium (Italy). APMIS. 2008;116(Suppl 124):74-6.

65. Flower RL, Kamhieh S, McLean L, Bode L, Ludwig H, Ward CM. Human Borna disease virus infection in Australia: serological markers of infection in multi-transfused patients. APMIS. 2008;116(Suppl 124):89-93.

66. Rackova S, Janu L, Kabickova H. Borna disease virus (BDV) circulating immunocomplex positivity in addicted patients in the Czech Republic: a prospective cohort analysis. BMC Psychiatry. 2010;10:70. https://doi.org/10. 1186/1471-244X-10-70

67. Mazaheri-Tehrani E, Maghsoudi N, Shams J, Soori H, Atashi H, Motamedi $F$, et al. Borna disease virus (BDV) infection in psychiatric patients and healthy controls in Iran. Virol J. 2014;11:161. https://doi.org/10.1186/ 1743-422X-11-161.

68. Liu X, Bode L, Zhang L, Wang X, Liu S, Zhang L, et al. Health care professionals at risk of infection with Borna disease virus - evidence from a large hospital in China (Chongqing). Virol J. 2015;12:39. https://doi.org/10. 1186/s12985-015-0239-y.
69. Wolff T, Heins G, Pauli G, Burger R, Kurth R. Failure to detect Borna disease virus antigen and RNA in human blood. J Clin Virol. 2006;36(4):309-11.

70. Jordan I, Briese T, Averett DR, Lipkin WI. Inhibition of Borna disease virus replication by ribavirin. J Virol. 1999;73(9):7903-6.

71. Tokunaga T, Yamamoto Y, Sakai M, Tomonaga K, Honda T. Antiviral activity of favipiravir (T-705) against mammalian and avian bornaviruses. Antivir Res. 2017;143:237-45. https://doi.org/10.1016/j.antiviral.2017.04.018.

72. Guedj J, Piorkowski G, Jacquot F, Madelain V, Nguyen THT, Rodallec A, et al. Antiviral efficacy of favipiravir against Ebola virus: A translational study in cynomolgus macaques. PLoS Med. 2018;15(3):e1002535. https://doi.org/10. 1371/journal.pmed.1002535.

73. Zarate CA Jr, Singh JB, Quiroz JA, De Jesus G, Denicoff KK, Luckenbaugh DA, et al. A double-blind, placebo-controlled study of memantine in the treatment of major depression. Am J Psychiatry. 2006;163(1):153-5.

74. Smith EG, Deligiannidis KM, Ulbricht CM, Landolin CS, Patel JK, Rothschild AJ. Antidepressant augmentation using the N-methyl-D-aspartate antagonist memantine: a randomized, double-blind, placebo-controlled trial. J Clin Psychiatry. 2013;74(10):966-73. https://doi.org/10.4088/JCP.12m08252.

75. Cubitt B, de la Torre JC. Amantadine does not have antiviral activity against Borna disease virus. Arch Virol. 1997;142(10):2035-42.

76. Hallensleben W, Zocher M, Staeheli P. Borna disease virus is not sensitive to amantadine. Arch Virol. 1997;142(10):2043-8.

77. Stitz L, Planz O, Bilzer T. Lack of antiviral effect of amantadine in Borna disease virus infection. Med Microbiol Immunol. 1998 Mar;186(4):195-200.

78. Gosztonyi G. Natural and experimental Borna disease virus infections-neuropathology and pathogenetic considerations. APMIS. 2008;116(Suppl 124):53-7 Review.

79. Bortolotto ZA, Clarke VR, Delany CM, Parry MC, Smolders I, Vignes M, et al. Kainate receptors are involved in synaptic plasticity. Nature. 1999;402(6759): 297-301.

80. Sihra TS, Flores G, Rodríguez-Moreno A. Kainate receptors: multiple roles in neuronal plasticity. Neuroscientist. 2014;20(1):29-43. https://doi.org/10.1177/ 1073858413478196 Review.

81. Dittrich W, Bode L, Ludwig H, Kao M, Schneider K. Learning deficiencies in Borna disease virus-infected but clinically healthy rats. Biol Psychiatry. 1989; 26(8):818-28.

\section{Publisher's Note}

Springer Nature remains neutral with regard to jurisdictional claims in published maps and institutional affiliations.
Ready to submit your research? Choose BMC and benefit from:

- fast, convenient online submission

- thorough peer review by experienced researchers in your field

- rapid publication on acceptance

- support for research data, including large and complex data types

- gold Open Access which fosters wider collaboration and increased citations

- maximum visibility for your research: over $100 \mathrm{M}$ website views per year

At BMC, research is always in progress.

Learn more biomedcentral.com/submission 